\title{
Two-phase deformation of lower mantle
}

\section{mineral analogs}

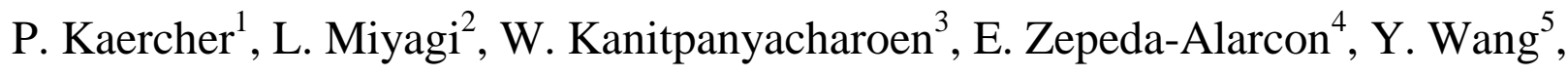
D. Parkinson ${ }^{6}$, R.A Lebensohn ${ }^{7}$ F. De Carlo ${ }^{5}$, H.R. Wenk ${ }^{4}$

\begin{abstract}
The lower mantle is estimated to be composed of mostly bridgmanite and a smaller percentage of ferropericlase, yet very little information exists for two-phase deformation of these minerals. To better understand the rheology and active deformation mechanisms of these lower mantle minerals, especially dislocation slip and the development of crystallographic preferred orientation (CPO), we deformed mineral analogs neighborite $\left(\mathrm{NaMgF}_{3}\right.$, iso-structural with bridgmanite) and halite ( $\mathrm{NaCl}$, iso-structural with ferropericlase) together in the deformationDIA at the Advanced Photon Source up to 51\% axial shortening. Development of CPO was
\end{abstract}


22 recorded in situ with X-ray diffraction, and information on microstructural evolution was

23 collected using X-ray microtomography. Results show that when present in as little as $15 \%$

24 volume, the weak phase $(\mathrm{NaCl})$ controls the deformation. Compared to single phase $\mathrm{NaMgF}_{3}$

25 samples, samples with just $15 \%$ volume $\mathrm{NaCl}$ show a reduction of $\mathrm{CPO}$ in $\mathrm{NaMgF}_{3}$ and

26 weakening of the aggregate. Microtomography shows both $\mathrm{NaMgF}_{3}$ and $\mathrm{NaCl}$ form highly

27 interconnected networks of grains. Polycrystal plasticity simulations were carried out to gain

28 insight into slip activity, CPO evolution, and strain and stress partitioning between phases for

29 different synthetic two-phase microstructures. The results suggest that ferropericlase may control

30 deformation in the lower mantle and reduce CPO in bridgmanite, which implies a less viscous

31 lower mantle and helps to explain why the lower mantle is fairly isotropic.

33 Keywords: crystallographic preferred orientation; seismic anisotropy; two-phase deformation;

34 lower mantle rheology; 3D X-ray microtomography

\section{Introduction}

Geodynamic models predict large strains due to convection in the lower mantle (e.g.

38 McNamara et al. 2002), which is composed primarily of $\sim 70 \%$ volume $(\mathrm{Mg}, \mathrm{Fe}) \mathrm{SiO}_{3}$ bridgmanite

39 and $\sim 25 \%$ volume $(\mathrm{Mg}, \mathrm{Fe}) \mathrm{O}$ ferropericlase with a few percent of $\mathrm{CaSiO}_{3}$ perovskite and some

40 Al-rich and silica phases. Understanding how these minerals deform under large strains is

41 important for constraining mantle rheology and for explaining seismic observations. Because the

42 bulk of the lower mantle is seismically isotropic (French and Romanowicz 2014), diffusion

43 creep, which typically does not promote crystallographic preferred orientation (CPO) and thus

44 seismic anisotropy, has long been assumed to be the dominant deformation regime in the lower 
mantle (e.g. Karato et al. 1995). However, recent deformation experiments of ferropericlase and bridgmanite aggregates find they do deform by dislocation creep at lower mantle pressures and temperatures (Girard et al. 2016). Polycrystal plasticity models suggest strong CPO will develop if the large strains in the lower mantle are accommodated by dislocation slip (Wenk et al. 2011). However, these models ignore the interaction of bridgmanite with weaker ferropericlase.

Ferropericlase is likely weaker than bridgmanite in the lower mantle (e.g. Amodeo et al. 2012, Kraych et al. 2016, Merkel et al. 2003). For deformation in a two-phase system with large strength contrast, microstructure greatly influences rheology (e.g. Handy 1994). For example, if the weaker ferropericlase is not interconnected, then rheology of the lower mantle will mostly depend on bridgmanite, but if ferropericlase is interconnected, then it will likely control deformation. Ferropericlase may not only influence the development of crystallographic preferred orientation and seismic anisotropy more than previously thought (e.g. Cottaar et al. 2014), but mantle mixing (Girard et al. 2016), viscosity (Yamazaki and Karato 2001) and slab stagnation (Marquardt and Miyagi 2015) as well.

The role of ferropericlase in lower mantle rheology is controversial. Resistivity measurements of bridgmanite-ferropericlase aggregates grown at $25 \mathrm{GPa}$ from ringwoodite found ferropericlase to be interconnected at $1300-1700 \mathrm{~K}$ and thereby likely to control the bulk deformation (e.g. Yamazaki et al. 2014). Aggregates of various proportions of $\mathrm{MgO}$ and $\mathrm{MgAl}_{2} \mathrm{O}_{4}$-spinel were deformed in the D-DIA at $5 \mathrm{GPa}$ and $800-1000^{\circ} \mathrm{C}$, with $\mathrm{MgO}$ accommodating the majority of strain and greatly weakening the aggregate at $25 \%$ volume (Li et al. 2007). In a recent study Girard et al. (2016) deformed $\sim 70 \%$ bridgmanite $+\sim 30 \%$ ferropericlase aggregates with isolated ferropericlase grains inside of a bridgmanite matrix in a rotational Drickamer apparatus up to $100 \%$ shear strain. They suggest ferropericlase controlled 
deformation based on observations of strain weakening, large strength contrast between the two

69 phases, and strain partitioning into ferropericlase, even though it was not interconnected. In

70 contrast, other studies find that if weaker ferropericlase is present in $\sim 25 \%$ volume, bridgmanite

71 controls deformation. For example finite element modeling (FEM) of deformation in

72 bridgmanite-ferropericlase aggregates by Madi et al. (2005) found bridgmanite limits

73 deformation even when both phases are highly interconnected. Wang et al. (2013) deformed 72\%

$74 \mathrm{CaGeO}_{3}$-perovskite $+28 \% \mathrm{MgO}$ with $\mathrm{MgO}$ as isolated grains in the microstructure in the D-DIA

75 up to $20 \%$ axial shortening and found that the bridgmanite analog $\left(\mathrm{CaGeO}_{3}\right)$ controlled

76 deformation.

77 Very few studies consider CPO (i.e. texture) development during deformation of lower

78 mantle polymineralic aggregates. Of the studies mentioned above, only Wang et al. (2013)

79 looked at $\mathrm{CPO}$ and found $\mathrm{CaGeO}_{3}$ developed similar $\mathrm{CPO}$ whether deformed as a single phase or

80 along with 28\% volume $\mathrm{MgO}$ while $\mathrm{MgO}$ developed weak CPO. Wenk et al. (2004) and Miyagi

81 and Wenk (2016) deformed ferropericlase-bridgmanite aggregates to $50 \mathrm{GPa}$ and $61 \mathrm{GPa}$,

82 respectively, in a diamond anvil cell (DAC) and found that ferropericlase developed a weak,

83 irregular texture when deformed with bridgmanite, and that bridgmanite texture changed

84 depending on the starting material and/or the presence of ferropericlase. Microstructures in the

85 DAC experiments were unknown but assumed to have ferropericlase not interconnected based on

86 earlier studies (e.g. Martinez et al. 1997), and thus attributed the lack of CPO in ferropericlase to

87 local heterogeneous deformation.

None of these studies considered the effect of ferropericlase volume percent on CPO

89 even though volume percent of ferropericlase in the lower mantle is estimated from geophysical

90 and geochemical data to be anywhere from 10-30\% (Irifune and Tsuchiya 2007) and is likely 
91 heterogeneously distributed in the lower mantle. Here we deformed two-phase lower mantle

92 mineral analogs with various volume percent of each phase in the D-DIA at high temperature

93 and pressure. Because the D-DIA cannot reach lower mantle pressures, we used analogs $\mathrm{NaCl}$

94 and $\mathrm{NaMgF}_{3}$, isostructural to ferropericlase and bridgmanite, respectively. X-ray diffraction

95 images were collected in situ to observe the development of CPO and stress distribution in the

96 two phases. We examined three-dimensional (3D) microstructures with X-ray microtomography

97 and estimate slip systems responsible for the observed CPO and the effect of microstructure on

98 stress and strain partitioning between phases with polycrystal plasticity models.

\section{Materials and methods}

\section{$101 \quad 2.1 \quad$ Analog minerals}

\section{$102 \quad 2.1 .1 \quad$ Neighborite}

$\mathrm{NaMgF}_{3}$ has a distorted cubic structure characterized by tilted $\mathrm{MgF}_{6}$ octahedra and

104 belongs to orthorhombic space group Pbnm. $\mathrm{NaMgF}_{3}$ was chosen as an analog mineral for

105 bridgmanite because it is isostructural to bridgmanite, yet deforms more easily at lower

106 pressures. In addition, $\mathrm{NaMgF}_{3}$ transitions to a $\mathrm{CaIrO}_{3}$-type post-perovskite structure at high

107 pressure, to tetragonal and cubic phases at high temperature, and dissociates at high pressures

108 and temperatures just as bridgmanite does (e.g. Zhao et al. 1994, Umemoto et al. 2006,

109 Umemoto and Wentzcovitch 2011).

110 It is less clear whether $\mathrm{NaMgF}_{3}$ has similar deformation mechanisms as bridgmanite.

111 Twinning has been observed in both $\mathrm{NaMgF}_{3}$ (e.g. Lewis and Bright 1971) and in bridgmanite

112 (e.g. Wang et al. 1990), and is commonly produced in perovskite structures, either during a phase

113 transition or by deformation. Most deformation is accommodated by slip, however slip systems 
114 in $\mathrm{NaMgF}_{3}$ have not been well studied, and the preferred slip systems of bridgmanite are still

115 debatable. Deformation experiments of bridgmanite in the DAC suggest a number of slip

116 systems on the (010), (001), and/or (100) planes (e.g. Merkel et al. 2003, Miyagi and Wenk

117 2016), experiments in the multianvil apparatus suggest slip along <100> at uppermost lower

118 mantle conditions (Cordier et al. 2004), and bonding calculations suggest (100)[010] slip at

119 lower mantle conditions (e.g. Mainprice et al. 2008, Kraych et al. 2016). Deformation textures

120 strongly show orthorhombic textures requiring orthorhombic rather than pseudo-cubic slip

121 systems (Wenk et al. 2006), which is yet another reason for selecting $\mathrm{NaMgF}_{3}$ with orthorhombic

122 symmetry rather than a cubic perovskite as an analog. Results presented in section 4.2.1 show

123 some similarity between CPO development and active slip systems in $\mathrm{NaMgF}_{3}$ and bridgmanite.

$124 \mathrm{NaMgF}_{3}$ was synthesized for this study from a stoichiometric mixture of $\mathrm{NaF}$ and $\mathrm{MgF}_{2}$

125 sintered at $750{ }^{\circ} \mathrm{C}$ (Appendix A).

126

127

\subsubsection{Halite}

$\mathrm{NaCl}$ was chosen as the analog for ferropericlase, because it is isostructural to

129 ferropericlase. Both minerals have a B1 structure, belonging to space group Fm $\overline{3} \mathrm{~m}$ at ambient conditions. The deformation behavior of single crystal $\mathrm{NaCl}$ (e.g. Carter and Heard 1970) and

131 periclase (e.g. Routbort 1979, Day and Stokes 1966) have been studied in detail. In both

132 minerals, the stiffest direction is parallel to the $a$-axis, and the easiest slip system is $\{110\}<1 \overline{1} 0>$, 133 with $\{111\}<1 \overline{1} 0>$ and $\{001\}<1 \overline{1} 0>$ becoming increasingly active at higher temperature.

The strength contrast between bridgmanite and ferropericlase (the ratio of maximum

135 differential stress supported by each phase) at upper lower mantle conditions has been estimated 136 to be about 5 to 10, depending on pressure and temperature (e.g. Amodeo et al. 2012, Kraych et 
137

138

139

140

141

142

143

144

145

146

147

148

149

150

151

152

153

154

155

156

157

158

159

al. 2016, Girard et al. 2016). Here we find the strength contrast between $\mathrm{NaMgF}_{3}$ and $\mathrm{NaCl}$ at pressures near $4 \mathrm{GPa}$ and temperatures $200-400^{\circ} \mathrm{C}$ to be $\sim 10$. If the strength contrast is higher in the analog system, so too may be the degree of stress and strain partitioning and the degree of connectivity of the weaker $\mathrm{NaCl}$ (Handy 1994).

\subsection{Deformation-DIA}

\subsubsection{Experiments}

Experiments were done in the D-DIA at GSECARS beamline 13-BM-D of the Advanced Photon Source (APS). The D-DIA is a multi-anvil press that can apply quasi-hydrostatic pressure up to $~ 15 \mathrm{GPa}$ and uniaxial differential stress separately while simultaneously resistively heating up to $2000^{\circ} \mathrm{C}$ (Wang et al. 2003).

Ten samples of various volume percent of $\mathrm{NaMgF}_{3}$ and $\mathrm{NaCl}$ were compressed quasihydrostatically to 20 tons ( $3-5 \mathrm{GPa})$ by driving in three sets of orthogonal pistons, then compressed uniaxially by advancing the differential rams (top and bottom pistons). Samples were deformed up to $\sim 51 \%$ axial shortening at average strain rates of $1.3 \times 10^{-3}$ to $3.4 \times 10^{-3} \mathrm{~s}^{-1}$ while being heated to temperatures ranging from $100^{\circ} \mathrm{C}$ to $800^{\circ} \mathrm{C}$ (Table 1). Diffraction images were collected in radial geometry (X-ray path is perpendicular to compression direction) with monochromatic X-rays $(\lambda=0.225-0.248 \AA)$ as pressure and strain increased. During compression, axial shortening of the samples was imaged with X-ray radiography using two 5 $\mu \mathrm{m}$ thick flakes of Au on the top and bottom of the sample for contrast. Axial shortening is defined as standard strain $\%=\Delta l / l_{0} \times 100$ where $l_{0}$ is the sample length after quasi-hydrostatic compression but before deforming. In a few experimental runs where the rams did not advance at the same rate as the load, causing slight sample extension, $l_{0}$ is taken as the sample length at 
ambient pressure. Since compression in D-DIA is never truly hydrostatic, $l_{0}$ is likely measured at non-zero strain in all cases.

\subsubsection{Data analysis}

Diffraction images were analyzed with Rietveld refinement as implemented in the software package MAUD (e.g. Lutterotti et al. 2014). Rietveld refinement is a least-squares method that minimizes the difference between the data and a calculated fit by iteratively refining various parameters such as diffraction background, phase volume percent, cell parameters, crystallite size, root mean square (r.m.s.) microstrain, lattice strain, and CPO. Pressure was calculated from the best fit for cell parameters and equation of state of $\mathrm{NaCl}$ or $\mathrm{NaMgF}_{3}$. Details of Rietveld refinement are given in Appendix B.

With Rietveld analysis we can quantify the differential stress and CPO in each phase. Deviatoric (non-hydrostatic) stress imposed on the sample leads to non-isotropic elastic lattice strain, which is exhibited as sinusoidal variations of diffraction peak position as a function of $\eta$ (the angle to the compression direction, i.e. the azimuthal angle) (Fig. A.1b). For each phase, the principle stresses in the deviatoric stress tensor $\left(\sigma_{11}, \sigma_{22}\right.$, and $\left.\sigma_{33}\right)$ can be calculated from the nonisotropic lattice strain and the elastic constants of $\mathrm{NaMgF}_{3}$ (Zhao and Weidner 1993) and $\mathrm{NaCl}$ (Liu et al. 2010); see Appendix B for details. Differential stress is defined as $\Delta \sigma=\sigma_{33}-\sigma_{11}$, where $\sigma_{33}$ is the principle stress in the direction of the loading axis, and $\sigma_{11}$ and $\sigma_{22}$ are the principal stresses perpendicular to the loading axis and are assumed to be equal. Here we define compressive stress to be negative and write $-\Delta \sigma$ to refer to compressive differential stress.

Plastic deformation by dislocation slip leads to rotation of crystallographic planes relative to a maximum stress direction and can result in CPO. The critical resolved shear stress (CRSS), 
183 i.e. the minimum stress required to activate slip in a set of crystallographic planes, of the possible 184 slip systems will determine the resulting texture. CPO is exhibited as regular intensity variations 185 in Debye rings along $\eta$ (Figs. A.1). It is described by an orientation distribution function (ODF) 186 and is plotted here as inverse pole figures (IPFs), which plot the density of poles of 187 crystallographic planes relative to the compression direction of the sample.

\subsection{Microtomography and microstructure}

\subsubsection{Microtomography experiments}

Microtomography non-destructively images the 3D structure of samples using phase contrast imaging. Phase connectivity and distribution of one undeformed sample and three deformed samples were quantified using microtomography at beamline 8.3.2 of the Advanced Light Source (ALS) and beamline 2-BM of the APS. using a small piece of clay. 1500 transmission images were collected while the sample was rotated $180^{\circ}$. Transmission images were corrected for inhomogenous illumination, normalized, 198 and reconstructed into slices that were stacked to render a 3D image. Each phase was 199 thresholded, and statistics were compiled in Avizo Fire 3D Analysis Software for Materials 200 Science (Visualization Sciences Group). For more details of microtomography setup, collection, 201 and analysis, see Appendix C.

\subsubsection{Scanning electron microscopy}

Since X-ray diffraction and microtomography could not resolve grain size in our samples, 205 a backscattered image of an undeformed $75 \% \mathrm{NaMgF}_{3}$, unpolished sample was collected in a 
207 to estimate grain size. The image was taken at 1000× magnification under elevated pressure so

208 that the sample did not need to be carbon coated. The large difference in hardness between the

209 two phases and the solubility of both phases in water, especially $\mathrm{NaCl}$, makes these samples very

210 challenging to prepare for EBSD requiring new polishing methods to be developed. In addition

211 kikuchi patterns of orthorhombic perovskite minerals like $\mathrm{NaMgF}_{3}$ that have two cell parameters

212 nearly equal in length are difficult to reliably index. Therefore we do not include further

213 microstructural analysis of these samples here but plan to present EBSD and SEM results in a 214 separate paper.

\section{Results}

Results are based on 120 X-ray diffraction images taken during ten experimental runs in the D-DIA. Errors of volume percent derived from X-ray diffraction patterns are roughly $\pm 0.2 \%$

219 in most cases, but can be as high as $\pm 4 \%$ (Table 1). These differ from percentages measured

220 before sintering by more than $4 \%$, which may be due to some powder being lost during the 221 sintering process and/or the fact that the X-ray beam samples only a small section of the sample 222 that might have slightly different composition.

\section{$224 \quad 3.1 \quad$ Differential stress}

A general trend of decreasing differential stress in $\mathrm{NaMgF}_{3}$ with increasing $\mathrm{NaCl}$ content 226 can be seen in Fig. 1 where the waviness (i.e. sinusoidal variation of peak positions along $n$ ) of $227 \mathrm{NaMgF}_{3}$ peaks decreased with increasing $\mathrm{NaCl}$ content. The $100 \% \mathrm{NaMgF}_{3}$ sample deformed at 228 lower temperature $\left(400^{\circ} \mathrm{C}\right)$ acquires the highest stress of $-\Delta \sigma_{\max }=2.25 \mathrm{GPa}$, which decreased to 
$1.35 \mathrm{GPa}$ for $85 \% \mathrm{NaMgF}_{3}, 1.24 \mathrm{GPa}$ for $75 \% \mathrm{NaMgF}_{3}$, and $<1 \mathrm{GPa}$ for $50 \% \mathrm{NaMgF}_{3}$ and $30 \%$ $\mathrm{NaMgF}_{3}$ samples (results for $400^{\circ} \mathrm{C}$ runs, Table 1 ).

Increasing temperature reduced differential stress in $\mathrm{NaMgF}_{3}$ and affected the $100 \%$ $\mathrm{NaMgF}_{3}$ sample the most, with stress reaching up to $-\Delta \sigma_{\max }=1.05 \mathrm{GPa}$ and averaging during steady state $-\Delta \sigma_{\mathrm{ave}}=0.74 \mathrm{GPa}$ at $800^{\circ} \mathrm{C}$, less than half of $-\Delta \sigma_{\max }=2.25 \mathrm{GPa}$ and $-\Delta \sigma_{\mathrm{ave}}=2.13$ $\mathrm{GPa}$ at $400^{\circ} \mathrm{C}$ (Table 1). The effect of temperature on $-\Delta \sigma$ in $\mathrm{NaMgF}_{3}$ decreases with increasing $\mathrm{NaCl}$ content as shown in Fig. $2 \mathrm{a}$, where the mean $-\Delta \sigma_{\max }$ for runs done at higher temperature (half-filled markers) plot far below the mean $-\Delta \sigma_{\max }$ for runs done at lower temperature (filled markers) in the $100 \% \mathrm{NaMgF}_{3}$ sample, but plot much nearer each other for the $75 \% \mathrm{NaMgF}_{3}$, $50 \% \mathrm{NaMgF}_{3}$, and $30 \% \mathrm{NaMgF}_{3}$ samples. The high temperature $100 \% \mathrm{NaMgF}_{3}$ run was done at $800^{\circ} \mathrm{C}$ compared to on $400^{\circ} \mathrm{C}$ on average in high temperature runs for other samples (Table 1). This may explain why the data point for average differential stress for high temperature $100 \%$ $\mathrm{NaMgF}_{3}$ falls below the best fit line in Fig. 2a.

Differential stress supported by $\mathrm{NaMgF}_{3}$ increased until about $20 \%$ strain in $100 \%$ $\mathrm{NaMgF}_{3}$ samples and until 10-15\% strain in two-phase samples when steady state deformation was reached (Fig. 2b). The drop in differential stress for the low temperature run of $85 \%$ $\mathrm{NaMgF}_{3}$ at about $40 \%$ strain and high temperature runs of $50 \% \mathrm{NaMgF}_{3}$ and $30 \% \mathrm{NaMgF}_{3}$ samples at about $33 \%$ strain in Fig. $2 \mathrm{~b}$ is due to a temperature increase at the end of those experiments.

Because $\mathrm{NaCl}$ yields plastically at lower stress than $\mathrm{NaMgF}_{3}$, it cannot support as much differential stress (lattice strain) before deforming plastically. This is seen in Fig. 1 where the $\mathrm{NaCl}$ peaks are relatively straight compared to $\mathrm{NaMgF}_{3}$. Differential stress in $\mathrm{NaCl}$ reached up to $-\Delta \sigma_{\max }=0.26 \mathrm{GPa}$, nearly an order of magnitude less than $\mathrm{NaMgF}_{3}$ at $-\Delta \sigma_{\max }=2.25 \mathrm{GPa}(\mathrm{Table}$ 
252 1), giving an estimated strength contrast for $\mathrm{NaMgF}_{3}-\mathrm{NaCl}$ of about10. With such little stress

253 development in $\mathrm{NaCl}$, no strong correlation is seen between differential stress and bulk strain or

254 sample composition (Fig. 2). Differential stress in $\mathrm{NaCl}$ slightly decreases at higher temperature

255 (Fig. 2a) and very slightly peaks at 10\% strain (Fig. 2b).

Using equations from Handy (1994), we estimate the total stress in the sample from the

257 phase volume percent and the average steady state stress $\left(-\Delta \sigma_{\mathrm{ave}}\right)$ in each phase for both an

258 interconnected weak layer (IWL) and a load bearing framework (LBF) microstructure (Table 1).

259 For samples with at least $50 \%$ volume $\mathrm{NaCl}$, especially those deformed at higher average

260 temperatures, the total $-\Delta \sigma$ estimated for an IWL $\left(-\Delta \sigma_{\text {IWL }}\right)$ agrees much better with the average -

$261 \Delta \sigma$ supported by $\mathrm{NaCl}$ than the total $-\Delta \sigma$ estimated for a LBF $\left(-\Delta \sigma_{\mathrm{LBF}}\right)$ agrees with $-\Delta \sigma$ supported

262 by $\mathrm{NaMgF}_{3}$. This suggests that the microstructures in these samples are closer to an IWL

263 microstructure, as expected. For samples with less than $50 \% \mathrm{NaCl}$, neither does $-\Delta \sigma_{\mathrm{IWL}}$ agree

264 well with the average $-\Delta \sigma$ supported by $\mathrm{NaCl}$ nor does $-\Delta \sigma_{\mathrm{LBF}}$ agree well with $-\Delta \sigma$ supported by

$265 \mathrm{NaMgF}_{3}$. This implies that the microstructures with lower $\mathrm{NaCl}$ content fall somewhere between 266 an IWL and a LBF.

$268 \quad 3.2 \quad$ Texture

$269 \mathrm{NaMgF}_{3}$ developed a pole density maximum at (100) in the IPFs for all compositions

270 (Fig. 3a), indicating that (100) lattice planes preferentially align perpendicular to the

271 compression direction. The (100) maximum extends toward $\{110\}$ and (001). This extension is

272 seen progressively less as the $\mathrm{NaMgF}_{3}$ volume percent decreases. For samples with $100 \%$

$273 \mathrm{NaMgF}_{3}$ content, a small secondary maximum is observed at (001). A small but representative 
274 subset of IPFs is shown in Fig. 3a; the full set of IPFs can be found in the appendix of Kaercher 275 (2014).

Texture strength (i.e. maximum pole density) in $\mathrm{NaMgF}_{3}$ strongly correlates to sample 277 composition (Fig. 4a). While $100 \% \mathrm{NaMgF}_{3}$ samples (white circles) developed very strong CPO 278 with pole densities reaching up to 11.8 m.r.d. (Table 1), samples containing just $15 \%$ volume $279 \mathrm{NaCl}$ have pole densities of up to 5.9 m.r.d, i.e. half the texture strength. Whereas texture 280 increased until the final strains in $100 \% \mathrm{NaMgF}_{3}$ samples, texture slightly decreased once $\sim 15 \%$ 281 strain was reached in all the two-phase samples (Fig. 4b).

283 pole density maxima reaching 11.8 m.r.d. at $400^{\circ} \mathrm{C}$ and 6.9 m.r.d. at $800^{\circ} \mathrm{C}$. On the other hand, 284 temperature had little effect on the two-phase samples. In samples containing $15 \% \mathrm{NaCl}$, the 285 maximum pole density of $\mathrm{NaMgF}_{3}$ at $200^{\circ} \mathrm{C}$ was 5.9 m.r.d., and at $400^{\circ} \mathrm{C}, 5.4$ m.r.d. For samples 286 with $25 \% \mathrm{NaCl}$ or more, the differences in texture strength in $\mathrm{NaMgF}_{3}$ at different temperatures 287 are negligible (Fig. 4b, Table 1). 
297 volume) reached the highest maximum pole density of 1.5 m.r.d., samples with $25 \%$ and $50 \%$

$298 \mathrm{NaCl}$ reached 1.2 m.r.d., and samples with the most $\mathrm{NaCl}(70 \% \mathrm{NaCl})$ reached 1.4 m.r.d. (Table

299 1). Neither temperature (Fig. 4a,b) nor strain \% (Fig. 4b) appear to correlate with texture in

$300 \mathrm{NaCl}$.

301

\section{$302 \quad 3.3 \quad$ Microstructure}

The spatial distribution of phases, grain cluster sizes, and aspect ratios were quantified with X-ray microtomography for one undeformed $75 \% \mathrm{NaMgF}_{3}$ sample and three samples

305 deformed to $32-34 \%$ strain with compositions $75 \% \mathrm{NaMgF}_{3}, 50 \% \mathrm{NaMgF}_{3}$, and $30 \% \mathrm{NaMgF}_{3}$.

306 Microtomography data was collected from $0.03 \mathrm{~mm}^{3}$ to $0.22 \mathrm{~mm}^{3}$ subvolumes which may

307 account for some inconsistencies between volume percent measured during sample preparation

308 and microtomography (Table 2). In addition, although great care was taken to threshold phases

309 according to their different absorption intensities during data processing, errors may still arise

310 since $\mathrm{NaMgF}_{3}$ and $\mathrm{NaCl}$ do not drastically differ in intensity (gray shade) and images are a bit

311 blurred.

A cross section taken with microtomography of an undeformed sample with $75 \%$

$313 \mathrm{NaMgF}_{3}$ and $25 \% \mathrm{NaCl}$ is shown in Fig 5a. Because neighboring grains of the same mineral in

314 our samples could not be discerned from each other with phase contrast imaging at microscale

315 resolution, statistics gathered from microtomography are not of individual grains but rather of

316 interconnected clusters of grains. However, much higher resolution images were collected with a

317 scanning electron microscope (Fig. 5b). Without true grain size gathered from electron

318 backscatter diffraction, our best estimate of $\mathrm{NaCl}$ (white) grain diameter is roughly 1-10 $\mu \mathrm{m}$, and $319 \mathrm{NaMgF}_{3}$ (gray) grain diameter is about 5-20 $\mu \mathrm{m}$. 
Although microtomography has lower resolution than SEM, it can be used to quickly and

321

322

324

325 326

\section{Discussion}

non-destructively reconstruct 3D images to micron resolution. A 3D reconstruction of a 75\% $\mathrm{NaMgF}_{3}$ undeformed sample and a $75 \% \mathrm{NaMgF}_{3}$ sample deformed to $32 \%$ strain (Fig. 6) were made by stacking microtomography slices similar to those shown in Fig. 5a. Compared to the undeformed reconstruction, the deformed reconstruction shows grain clusters shortened in the compression direction and elongated in planes perpendicular to compression; the $\mathrm{NaCl}$ appears to fill in between the $\mathrm{NaMgF}_{3}$ grain clusters (Fig. 6c).

Quantitative results are shown in Table 2. Connectivity is defined here as the percent of the total phase volume contained in the largest, interconnected cluster of grains of that phase and was calculated by dividing the volume of the largest cluster of grains of a phase by the total volume of the phase. Both $\mathrm{NaMgF}_{3}$ and $\mathrm{NaCl}$ in the $75 \% \mathrm{NaMgF}_{3}$ sample are $>99 \%$ connected before deformation. $\mathrm{NaCl}$ may not appear to be highly interconnected in two dimensions, so we include the 3D reconstruction of $\mathrm{NaCl}$ only in Fig. 6a to help show that it is. In the $75 \% \mathrm{NaMgF}_{3}$ sample, connectivity of $\mathrm{NaMgF}_{3}$ remained constant during deformation while connectivity of $\mathrm{NaCl}$ decreased. In both phases, grain cluster size increased during deformation. Decreased connectivity and increased clustering of $\mathrm{NaCl}$ in the $75 \% \mathrm{NaMgF}_{3}$ sample may be due to $\mathrm{NaCl}$ squeezing between $\mathrm{NaMgF}_{3}$ grain clusters in the planes perpendicular to compression to form sheets while becoming less connected in the compression direction. As expected, the majority of $\mathrm{NaMgF}_{3}$ and $\mathrm{NaCl}$ grain clusters in the undeformed sample have aspect ratio $\approx 1$, while the majority in deformed samples have aspect ratios $>1$. Aspect ratio is the ratio of the longest dimension in $3 \mathrm{D}$ of a grain cluster to the shortest dimension. 


\section{$343 \quad 4.1 \quad$ Experimental deformation}

$344 \quad$ 4.1.1 Differential stress

Our results suggest that $\mathrm{NaCl}$ controls deformation. The average differential stress in $100 \% \mathrm{NaMgF}_{3}$ samples is about $40 \%$ greater than in $\mathrm{NaMgF}_{3}$ in $85 \% \mathrm{NaMgF}_{3}$ samples

347 deformed at similar conditions, suggesting that $\mathrm{NaCl}$ absorbs much of the plastic deformation at 348 just $15 \%$ volume. In addition, microtomography shows both $\mathrm{NaCl}$ and $\mathrm{NaMgF}_{3}$ to be 349 interconnected in our samples (Table 2).

Differential stress in $\mathrm{NaCl}$ is up to an order of magnitude less than in $\mathrm{NaMgF}_{3}$ in all

351 samples, demonstrating that stress partitions into the stronger $\mathrm{NaMgF}_{3}$ phase. We show in

352 section 4.2.2 with viscoplastic modeling that strain likely localizes into the weaker $\mathrm{NaCl}$ phase.

353 The shape change of $\mathrm{NaCl}$ clusters during deformation (Fig. 6c) also suggests that $\mathrm{NaCl}$ uptakes 354 much of the strain, but we cannot quantify this from microtomography data since results are of 355 grain clusters rather than single grains. All lower mantle deformation studies discussed here 356 agree that stress partitions into the stronger phase, and strain into the weaker phase, yet not all 357 agree that the weaker phase is interconnected and controls deformation (Madi et al. 2005, Li et 358 al. 2007, Wang et al. 2013, Girard et al. 2016, Miyagi and Wenk 2016). Disagreement among these studies about which phase controls deformation may stem from differences in final strain. Madi et al. (2005) and Wang et al. (2013) deformed aggregates

361 to $15 \%$ and $20 \%$ bulk strain, respectively, and found the stronger perovskite phase controls

362 deformation. However, Madi et al. (2005) mention that ferropericlase begins to form layers or 363 "pancakes" perpendicular to compression much like we see in $\mathrm{NaCl}$ (Fig. 6c) at higher strain. 364 Similarly, Girard et al. (2016) shows flattened ferropericlase grains at their final 100\% bulk 365 strains and suggest that the stronger phase controls deformation at lower strains $(<20 \%)$, but the 
weaker phase controls deformation at higher strains. We see a reduction of differential stress in $\mathrm{NaMgF}_{3}$ with the addition of $\mathrm{NaCl}$ already at strains $<10 \%$ (Fig. 2b) suggesting that $\mathrm{NaCl}$ accommodates a large portion of differential stress even at low strains.

Starting microstructure may also influence which phase controls deformation, but the relationship between phase connectivity and which phase controls deformation is not clear-cut: there are examples of the strong phase controlling deformation when the weak phase is interconnected (e.g. Madi et al. 2005), and the weak phase controlling deformation when it is not interconnected (e.g. Girard et al. 2016).

The controlling phase may also be determined by phase strength contrast. Estimated strength contrast is greater in studies that find that the weak phase controls deformation (Girard et al. 2016, Li et al. 2007, this study) compared to studies that find the stronger perovskite phase controls deformation (Madi et al. 2005, Wang et al. 2013). Here $\mathrm{NaCl}$ controls deformation at only $15 \%$ volume, which may be due to a higher strength contrast for $\mathrm{NaMgF}_{3}-\mathrm{NaCl}$ compared to other composites mentioned here. Then again Li et al. (2007) and Girard et al. (2016) may have found ferropericlase controls deformation at only $15 \%$ volume as well, but they had no samples with ferropericlase volume between 0 and $25 \%$.

Differential stress in $\mathrm{NaCl}$ is about the same for all compositions whereas differential stress in $\mathrm{NaMgF}_{3}$ decreases with increasing $\mathrm{NaCl}$ content (Fig. 2b). Thus the stress becomes more evenly distributed among the two phases as $\mathrm{NaCl}$ content increases and bears more of the strain, modulating the stress. This is consistent with $\mathrm{NaMgF}_{3}$ becoming less interconnected (Table 2), thus having less contact with the pistons and bearing less of the load. Temperature also causes stress to be more homogeneously distributed among the two phases (Fig. 2a). 

overall trend of either strain hardening or strain weakening in either phase during steady state deformation (Fig. 2a). By comparison, Girard et al. (2016) observed strain hardening in aggregates up to $20 \%$ strain, followed by a hint of strain weakening in bridgmanite to their final

392 strain of $\sim 100 \%$. It is possible that Girard et al. (2016) sees strain weakening because they 393 deformed samples in shear, while we deformed our samples under uniaxial compression. Shear 394 localization may occur in both cases but is less likely to lead to strain weakening in compression 395 because shear bands do not tend to align with each other as much as they do in shear strain.

\subsubsection{Texture}

We find a (100) maximum in $\mathrm{NaMgF}_{3}$ at all conditions in all samples. A secondary maximum at (001) and extension of the (100) maximum toward $\{110\}$ and (001) is observed in

$400 \mathrm{NaMgF}_{3}$ in samples with little or no $\mathrm{NaCl}$. It is unclear if this texture is similar to that of 401 bridgmanite at mantle conditions. While some DAC experiments report little to no CPO 402 development in bridgmanite (Meade et al. 1995, Merkel et al. 2003), others suggest bridgmanite 403 develops significant texture that varies depending on the starting material. For example, a (001) 404 transformation texture was observed in bridgmanite just after conversion from enstatite that 405 remained up to $56 \mathrm{GPa}$ (Miyagi and Wenk 2016). Wenk et al. (2004) and Miyagi and Wenk 406 (2016) both saw a (100) transformation texture in bridgmanite immediately after converting from 407 olivine or ringwoodite to bridgmanite + ferropericlase. Yet Wenk et al. (2004) found a 408 subsequent weak $\{012\}$ deformation texture while Miyagi and Wenk (2016) saw a (001) 409 deformation texture at lower pressure followed by a (100) maximum at pressure $>55 \mathrm{GPa}$. If 
410 bridgmanite develops a (100) deformation texture in the lower mantle due to dislocation creep,

411 then $\mathrm{NaMgF}_{3}$ is a good analog. We explore likely slip systems in the next section.

$\mathrm{NaCl}$ in samples with at least $25 \% \mathrm{NaCl}$ acquire pole density maxima at $\{001\}$ or $\{101\}$

413 in IPFs (Fig. 4), consistent with previous uniaxial compression studies of $\mathrm{NaCl}$ (e.g. Franssen

414 1994) and polycrystalline ferropericlase deformed in a DAC (Merkel et al. 2002). However,

415 samples containing $<25 \% \mathrm{NaCl}$ instead acquire weak maxima at $\{112\}$ and $\{101\}$. A similar

416 texture was observed for ferropericlase in bridgmanite-ferropericlase assemblages deformed in

417 the DAC and was attributed to heterogeneous deformation (Wenk et al. 2004, Miyagi and Wenk

418 2016). Weak ferropericlase textures were also observed by Wang et al. (2013). Under simple

419 shear deformation, texture development may be even weaker than in compression experiments.

420 Wenk et al. (2009) showed that weak texture is observed for $\mathrm{NaCl}$ deformed in plain shear

421 because crystals continue to rotate without converging on a single component.

422 Temperature greatly reduced $\mathrm{CPO}$ in the $100 \% \mathrm{NaMgF}_{3}$ samples, possibly due to

423 additional slip systems becoming more active at higher temperature, thereby decreasing the (100)

424 texture of $\mathrm{NaMgF}_{3}$ (e.g. Poirier et al. 1989) or possibly by decreased dislocation mechanisms and

425 increased diffusion. The effect of temperature on two-phase samples was much less and even

426 negligible in samples containing $50 \% \mathrm{NaCl}$ or more. Temperature may have less effect on

427 texture in two-phase samples due to $\mathrm{NaCl}$ pinning grain boundaries of $\mathrm{NaMgF}_{3}$ and thereby

428 limiting dislocation climb and glide at both lower and higher temperatures (e.g. Herwegh and

429 Berger 2004). Alternatively, it could be that $\mathrm{NaCl}$ absorbs the same amount of deformation

430 without developing significant CPO at both low and high temperatures, leaving less to be

431 accommodated by dislocation slip in $\mathrm{NaMgF}_{3}$. 
As stress builds in $\mathrm{NaMgF}_{3}$, it begins to deform plastically, initiating dislocation slip. On

433

434

435

436

437

438

439

440

441

442

443

444

445

446

447

448

449

450

451

452

453

454

the other hand, $\mathrm{NaCl}$ has lower elastic constants and does not support as much stress as $\mathrm{NaMgF}_{3}$. It also develops a much weaker texture either because it deforms by a mechanism that does not produce crystallographic $\mathrm{CPO}$, or it may be deforming heterogeneously between neighboring $\mathrm{NaMgF}_{3}$ grains and so does not acquire an overall CPO.

\subsection{Polycrystal plasticity simulations}

\subsubsection{Self-consistent model (VPSC)}

We performed viscoplastic self-consistent (VPSC) modeling (Lebensohn and Tomé 1993) to investigate likely slip system activities during experiments. VPSC allows grain inclusions of multiple phases to deform by dislocation slip in a homogenous medium that has the average properties of the composite (Eshelby 1957). Deformation and rotation of grains depends on their orientation relative to compression and the relative critical resolved shear stress (CRSS) of the slip systems. By comparing textures produced by VPSC simulations with experimental textures, we can estimate slip systems that were active during the experiment.

In our VPSC models, 2000 grains of each $\mathrm{NaMgF}_{3}$ and $\mathrm{NaCl}$, present in various volume percent, were compressed to $30 \%$ equivalent strain in $1 \%$ increments. Grains of both $\mathrm{NaMgF}_{3}$ and $\mathrm{NaCl}$ had little to no texture before deformation in experiments, and thus were prescribed a random orientation distribution at the start of VPSC simulations. A stress exponent of $n=3$ was assumed (Frost and Ashby 1982).

Our first approximation of slip system activity in $\mathrm{NaMgF}_{3}$ assumed that slip on (100) produced the pole density maximum seen at (100) in experimental IPFs (Fig. 3a). Thus we assigned (100)[010] and (100)<011> slip systems the lowest relative CRSS of 0.5, and varied 
455 relative CRSS of additional slip systems until we found the closest match to experimental texture

456 as possible. Relative CRSS and resulting slip system activities are listed in Table 3 . Because

457 twinning is common in perovskite-structured minerals, we also modeled twinning of

$458\{110\}<1 \overline{1} 1>$ with VPSC, which produced a very weak maximum at 100 , and thus may slightly

459 contribute to the (100) pole density maximum (Fig. 4b). No combination of slip systems

460 reproduced both the maximum at (100) and the secondary maximum at (001) seen in $100 \%$

$461 \mathrm{NaMgF}_{3}$, which suggests a small degree of strain heterogeneity in single phase $\mathrm{NaMgF}_{3}$. We are

462 not aware of any previous studies of slip systems in $\mathrm{NaMgF}_{3}$ with which we can compare results

463 here. However, similar to our results for $\mathrm{NaMgF}_{3}$, Miyagi and Wenk (2016) suggest preferential

464 slip on (100)[010] or $(100)<011>$ in bridgmanite above $55 \mathrm{GPa}$. Numerical models also find slip

465 on (100) most likely at higher pressure (Mainprice et al. 2008, Kraych et al. 2016).

VPSC results with slip on $\{110\}<1 \overline{1} 1>$ show a closest match to experimental $\mathrm{NaCl}$

467 textures with maxima at $\{100\}$ and $\{110\}$ (Fig. 3b) in agreement with studies of slip during

468 uniaxial compression in $\mathrm{NaCl}$ (e.g. Franssen 1994) and in (Mg,Fe)O (e.g. Merkel et al. 2002,

469 Kaercher et al. 2012). The slip systems $\{110\}<1-11>$ and $\{1-10\}<111>$ have equal Schmidt

470 factors and rotate crystallographic planes in opposite directions, essentially cancelling each other

471 and so are not expected to produce texture. However, a VPSC study of $\mathrm{NaCl}$ that takes grain

472 shape into account showed that texture increasingly develops with deformation as grain aspect

473 ratios increase (Wenk et al. 1989).

474 Pole density maxima predicted by VPSC for both $\mathrm{NaMgF}_{3}$ and $\mathrm{NaCl}$ decreased with the 475 addition of $\mathrm{NaCl}$, but not as much as observed in experiments (Fig. 3a,b). VPSC overestimates 476 pole densities likely because it assumes that all deformation occurs by dislocation glide, and it 477 does not take into account interaction between grains of different phases having different elastic 
478 and plastic properties, shapes, and crystallographic orientations. Thus VPSC simulations, which

479 only consider the interaction among individual grains and the homogenous equivalent medium,

480 underestimate stress and strain heterogeneity and are not ideal for modeling two-phase

481 deformation.

482

\subsubsection{Viscoplastic model using fast Fourier transform (VPFFT)}

We also modeled two-phase viscoplastic deformation with a method that uses fast Fourier transforms (VPFFT) and Greens functions to solve the governing equations for stress and strain rate in response to an applied strain at regularly-spaced grid points in a chosen 3D microstructure

487 (Lebensohn 2001). Individual grain orientations, shapes, grain-grain interactions, and

488 intragranular heterogeneity of the micromechanical fields are considered, making it well-suited 489 for simulating deformation in a heterogeneous two-phase composite.

Three periodic "random" microstructures with equant grains of $\mathrm{NaMgF}_{3}$ and $\mathrm{NaCl}$

491 present in different volume percent $\left(100 \% \mathrm{NaMgF}_{3}, 75 \% \mathrm{NaMgF}_{3}-25 \% \mathrm{NaCl}\right.$ and $50 \%$

$492 \mathrm{NaMgF}_{3}-50 \% \mathrm{NaCl}$ ), and one "percolate" microstructure with $25 \%$ volume $\mathrm{NaCl}$ sitting as veins

493 between equant $\mathrm{NaMgF}_{3}$ grains were created using Voronoi tessellations (Voronoi 1908) and are

494 shown in Fig. 7. $\mathrm{NaCl}$ grains were made roughly five times smaller than $\mathrm{NaMgF}_{3}$ grains based

495 on relative grain sizes seen in Fig. 5 b. The $3 \mathrm{D}$ grain maps were discretized into a $64 \times 64 \times 64$

496 grid of Fourier points. In the $75 \% \mathrm{NaMgF}_{3}$ random microstructure, $96.4 \%$ of $\mathrm{NaCl}$ Fourier points

497 are contained in one interconnected grain cluster, and in the $25 \% \mathrm{NaMgF}_{3}$ random and $75 \%$

$498 \mathrm{NaMgF}_{3}$ percolate microstructures, $\mathrm{NaCl}$ Fourier points are $100 \%$ interconnected, similar to

499 experimental microstructures (Table 2). Grains may shorten but must maintain constant volume

500 (e.g. they cannot break or grow), and connectivity does not change during deformation in these 
501 simulations. Initial orientation of grains was assigned as random to be consistent with

502 experimental observations. The same relative CRSS used in VPSC simulations (Table 3) were

503 assigned here as well. Stress was defined as axial compressive to a total strain of $30 \%$ in

504 increments of $2 \%$ strain.

While the $75 \% \mathrm{NaMgF}_{3}$ "random" microstructure IPF (Fig. 3c) shares the (100) pole

506 density maximum seen in the experimental 75\% $\mathrm{NaMgF}_{3}$ IPF (Fig. 3a), the "percolate"

507 microstructure IPF (Fig. 3c) shares the extension of the (100) $\mathrm{NaMgF}_{3}$ maximum toward $\{110\}$

508 and a secondary maximum that resembles the extension towards (001) and more accurately

509 matches the maximum pole densities for both $\mathrm{NaMgF}_{3}$ and $\mathrm{NaCl}$. This suggests a hybrid of

510 "random" and "percolate" microstructures in experimental samples, conceivably with the

511 majority of clusters of $\mathrm{NaCl}$ lying in planes perpendicular to compression and thinner and fewer

512 networks of $\mathrm{NaCl}$ connecting these planes, similar to the deformed microstructure seen in Fig.

$5136 c$.

VPFFT predicts similar slip system activities as VPSC for "random” microstructures, but

515 with slightly more homogenously distributed slip activity. This correlates with smoother textures

516 in VPFFT IPFS, because in contrast to VPSC simulations in which every point in a grain

517 experiences the same plastic distortion, VPFFT allows deformation states among points in the

518 same grain to deviate from each other. Other differences arise from VPFFT providing exact

519 solutions while VPSC approximates non-linear behaviour with a linearization scheme

520 (Lebensohn et al. 2016). The smoother textures predicted by the VPFFT model more closely

521 match experimental two-phase aggregate textures, while sharper VPSC textures more closely

522 resemble experimental $100 \% \mathrm{NaMgF}_{3}$ textures (Fig. 3). 
In both VPSC and random microstructure VPFFT simulations, the percent of deformation

524 accommodated by secondary slip systems in $\mathrm{NaMgF}_{3}$ increases with increasing $\mathrm{NaMgF}_{3}$ content

525 (Table 3). However this increased activity of secondary slip systems in the random 100\%

$526 \mathrm{NaMgF}_{3}$ and $75 \% \mathrm{NaMgF}_{3}$ microstructures fails to reproduce the extension of the (100)

527 maximum toward $\{110\}$ and (001) seen in the experimental $\mathrm{NaMgF}_{3}$ IPFs (Fig. 3). Instead in the

528 VPFFT microstructures with the least amount of secondary slip system activity, $25 \% \mathrm{NaMgF}_{3}$

529 random and $75 \% \mathrm{NaMgF}_{3}$ percolate microstructures, acquire the extension of the (100)

530 maximum towards $\{110\}$ and (001), suggesting that the extension becomes more pronounced if

531 deformation is accommodated by slip solely on (100). Results for the "percolate" microstructure

532 show much greater activity in $\mathrm{NaCl}$ compared with the random microstructure (Table 3 ) showing

533 it accommodates a greater percent of the total deformation as a thin network.

534 The relationship between microstructure, strain rate, and stress is best viewed as 2D

535 slices rather than as 3D projections, thus in Fig. 7 we show slices through the 3D microstructure

536 along with associated maps of von Mises equivalent strain rates and stresses shown as scalar

537 quantities. Strain rate maps in Fig. 7 (middle row) show that strain partitions into the weaker

$538 \mathrm{NaCl}$, especially in the "percolate" microstructure. This agrees with flow laws outlined by Handy

539 (1994) that predict strain localization in the weak phase in aggregates with an interconnected

540 weak layer (IWL) microstructure. In such structures, the strain rate in the weak phase correlates

541 to the strength contrast and volume percent of the two phases. Strain rate is most heterogeneous

542 in $\mathrm{NaCl}$ in two-phase samples with higher $\mathrm{NaMgF}_{3}$ volume percent, especially in the "percolate"

543 microstructure, which may help explain the weak and irregular textures seen in $\mathrm{NaCl}$ IPFs. Strain

544 rates are greatest and most heterogeneous in $\mathrm{NaMgF}_{3}$ in the $100 \% \mathrm{NaMgF}_{3}$ sample, and unlike 
545 for VPSC simulations, a very small secondary maximum appears at (001) in the IPF that matches

546 the experimental IPF for $100 \% \mathrm{NaMgF}_{3}$.

547 Stress maps in the bottom row of Fig. 7 show that $\mathrm{NaMgF}_{3}$ supports more stress than

$548 \mathrm{NaCl}$ in all samples, which we also observed in experiments. Stress is greatest and most

549 heterogeneous in $\mathrm{NaMgF}_{3}$ in the $100 \% \mathrm{NaMgF}_{3}$ sample. Differential stresses were calculated for

550 each phase in all microstructures, and we find that the model underestimates the ratio of

551 differential stress $\left(-\Delta \sigma_{\mathrm{NaMgF} 3} /-\Delta \sigma_{\mathrm{NaCl}}\right)$ supported in two-phase samples compared with

552 experiments: $-\Delta \sigma_{\mathrm{NaMgF} 3} /-\Delta \sigma_{\mathrm{NaCl}}$ in the $25 \% \mathrm{NaMgF}_{3}$ and $75 \% \mathrm{NaMgF}_{3}$ random microstructures is

5532.47 and 6.06, respectively, and in the $75 \% \mathrm{NaMgF}_{3}$ percolate microstructure, 3.35 ; in

554 comparison $-\Delta \sigma_{\mathrm{NaMgF} 3} /-\Delta \sigma_{\mathrm{NaCl}}$ for maximum stresses in experimental samples $30 \% \mathrm{NaMgF}_{3}$ and

$555 \quad 75 \% \mathrm{NaMgF}_{3}$ is 4.13 and 8.71 , respectively.

Here we focus on dislocation slip as the active deformation mechanism, but it should be

557 mentioned that the lack of $\mathrm{CPO}$ development in $\mathrm{NaCl}$, its small grain size $(\leq 1 \mu \mathrm{m})$ seen with

558 SEM (Fig. 5b), and change in connectivity and grain cluster size of $\mathrm{NaCl}$ during deformation

559 (Table 2, Fig. 6) may suggest grain-size sensitive creep mechanisms accommodated by grain

560 boundary sliding. Likewise, previous studies have found deformation controlled by secondary

561 phases occurs by Nabarro-Herring creep and/or Coble creep due to grain growth being limited by

562 a secondary phase (e.g. calcite-anhydrite, Barnhoorn et al. 2005). However, flattened grain

563 clusters seen in Fig. 6c suggest the sample deformed by plasticity, not by diffusion creep. The

564 weak texture of $\mathrm{NaCl}$ may well result from heterogeneous deformation by dislocation slip and

565 not lack of dislocation slip. It is also possible that the dominant deformation regime evolves with

566 strain and microstructural changes. For example, Li et al. (2007) argue for $\mathrm{MgO}$ deforming in 
567 power law creep by dynamic recrystallization, and because of the presence of a second phase,

568 grain size is reduced, so they suggest there may be a switch to grain-size sensitive creep.

$570 \quad 4.3 \quad$ Implications for the lower mantle

571 At axial strains up to $51 \%, \mathrm{CPO}$ in the bridgmanite analog, $\mathrm{NaMgF}_{3}$, was notably lower

572 in two-phase samples compared with single phase $\mathrm{NaMgF}_{3}$ (Fig. 4b), which suggests that weaker

573 phases, like ferropericlase, may absorb deformation without significantly contributing to CPO

574 and in fact will likely reduce CPO in the perovskite phase. This may explain the lack of

575 anisotropy in the lower mantle. This view differs somewhat from that of Girard et al's (2016),

576 which suggests that deformation is localized (based on observed strain weakening in their

577 samples) leaving the majority of the lower mantle undeformed and thus without CPO and

578 anisotropy. However, we do not see strain weakening here despite the larger rheology contrast

579 between $\mathrm{NaMgF}_{3}$ and $\mathrm{NaCl}$ compared to bridgmanite and ferropericlase. Even so, strain

580 weakening may still occur in areas of high simple shear strain as opposed to areas of pure shear

581 strain.

582 We find lower differential stress at all strains (Fig. 2b) in two-phase samples compared to

583 single phase $\mathrm{NaMgF}_{3}$ suggesting that weaker ferropericlase will reduce lower mantle strength

584 even at low strains. This suggests by analogy that $\mathrm{MgO}$ may play a major role in determining

585 lower mantle strength. If $\mathrm{MgO}$ is the deformation controlling phase in the lower mantle, it will

586 not only affect CPO but also determine viscosity and affect geodynamical processes such as plate

587 motion (Tackley 2000), slab subduction and stagnation (Marquardt and Miyagi 2015), mantle

588 plumes and hotspots (French and Romanowicz 2015), and relatedly, variation in ocean island

589 basalt geochemistry (Li et al. 2014). 
As discussed above, analog minerals may deform differently elastically and plastically

591 than their lower mantle counterparts. For example, differences in slip system activities between analogs and lower mantle minerals could result in a different seismic signature if CPO develops. Partitioning of stress and strain of bridgmanite and ferropericlase may vary from that of $\mathrm{NaMgF}_{3}$ and $\mathrm{NaCl}$ depending on strength contrast at lower mantle conditions. In addition our starting microstructure for $75 \% \mathrm{NaMgF}_{3}-25 \% \mathrm{NaCl}$ samples had $\mathrm{NaCl}$ already highly interconnected, whereas a eutectoid microstructure is expected at the top of the lower mantle after dissociation from $\mathrm{Mg}_{2} \mathrm{SiO}_{4}$ phases. However, even in the case of a starting microstructure with isolated ferropericlase, it may still control deformation (Girard et al. 2016). Conditions in the lower mantle, such as strain rate, grain sizes, and temperature, which affect deformation, may differ from those in our experiments. For example, slip is less active at lower strain rate in $\mathrm{NaCl}$ (Carter and Heard 1970) and MgO (Routbort 1979), which suggests that CPO may be even less in the lower mantle (strain rates of $\sim 10^{-14} \mathrm{~s}^{-1}$ ) than in D-DIA experiments $\left(\sim 10^{-3} \mathrm{~s}^{-1}\right)$. Calculations of grain sizes in the upper-most lower mantle that take into account Zener pinning during twophase growth by grain-boundary diffusion estimates grain sizes on the order of $100-1000 \mu \mathrm{m}$ (Solomatov et al. 2002), which is 1 to 2 orders of magnitude larger than grains in our experiments and may result in grain-size independent mechanisms, such as dislocation creep, being more active (e.g. Frost and Ashby 1982) and may enhance CPO. At higher temperatures, dislocation creep may become less active or may, on the other hand, lead to larger grain growth making dislocation creep more active. Results here indicate that temperature did not greatly affect CPO development in two-phase samples, but has a stronger effect on aggregate strength (Fig. 2b). 


\section{Conclusion}

We present evidence that ferropericlase may become interconnected in the lower mantle,

615 leading to reduced viscosity and weakening of CPO. These results reiterate the importance of

616 including the effect of secondary phase ferropericlase on rheology in geophysical models of the

617 lower mantle.

While our results strongly suggest reduction of CPO due to ferropericlase controlling

619 deformation, results presented here cannot constrain which deformation mechanism is

620 responsible for CPO reduction. Future systematic deformation experiments on bridgmanite -

621 ferropericlase aggregates coupled with in situ microtomography and/or ex situ electron

622 microscopy may help to construct deformation maps that can be extrapolated to better constrain

623 likely deformation mechanisms in the lower mantle. Such experiments are becoming

624 increasingly feasible (with larger, more easily recoverable samples) thanks to increased pressure

625 range of large volume presses (T-cups, Drickamer, D-DIA). Alternatively two-phase

626 deformation of lower mantle minerals may be predicted by comprehensive models that allow for

627 not only dislocation slip but also grain nucleation, grain growth, grain-boundary migration and

628 lattice diffusion creep. In addition, the effects of starting microstructure, strength contrast, and

629 aggregate strain should be looked at more closely. The starting microstructure here had $\mathrm{NaMgF}_{3}$

630 and $\mathrm{NaCl}$ already highly connected. Future experiments should be done to compare results for

631 samples with different starting microstructures. As shown here, the viscoplastic fast Fourier

632 transform-based approach is a valuable tool for predicting stress and strain partitioning and CPO

633 development in polyphase samples with different starting microstructures. We compare results

634 here to previous studies to examine the role strength contrast between the two phases plays in

635 determining the deformation-controlling phase and suggest that this may evolve with strain, but 
636 more systematic studies are necessary. Modeling of two-phase deformation using VPFFT or

637 finite element methods may be best suited for this pursuit as well.

638

639 Acknowledgements

640 This work was supported by CDAC and NSF grant EAR-1343908, NSF/CSEDI 1067513. LM

641 acknowledges support from CDAC and NSF grant EAR-1344579. YW acknowledges support

642 from NSF grant EAR-136127. Portions of this work were performed at GeoSoilEnviroCARS

643 (Sector 13) and beamline 2-BM-B (XOR) of the Advanced Photon Source (APS), Argonne

644 National Laboratory, which is supported by the National Science Foundation - Earth Sciences

645 and the Department of Energy. We thank the Advanced Light Source (ALS) of the Lawrence

646 Berkeley National Laboratory (LBNL) for the use of beamline 8.3.2. P. Kaercher is grateful to

647 David Martin for providing a beautiful sample of neighborite and to James Wu for his help in

648 synthesizing neighborite. All authors greatly appreciate the constructive comments from all three

649 reviewers. 
Tables

\begin{tabular}{|c|c|c|c|c|c|c|c|c|c|c|c|c|c|c|c|}
\hline \multirow[b]{3}{*}{ Run } & \multicolumn{5}{|c|}{ Experimental parameters } & \multicolumn{4}{|c|}{$\mathrm{NaMgF}_{3}$} & \multicolumn{4}{|l|}{$\mathrm{NaCl}$} & \multirow{2}{*}{$\begin{array}{l}\text { IWL } \\
-\Delta \sigma\end{array}$} & \multirow{2}{*}{$\begin{array}{l}\text { LBF } \\
-\Delta \sigma\end{array}$} \\
\hline & & & & & & IPF m & & $-\Delta \sigma$ & & IPF m & & $-\Delta \sigma$ & & & \\
\hline & $\begin{array}{l}V_{\mathrm{NaMgF} 3} \\
\mathrm{~S} / \mathrm{X}(\%)\end{array}$ & $\begin{array}{l}P_{\text {ave }} \\
(\mathrm{GPa})\end{array}$ & $\begin{array}{l}T_{\text {mode }} \\
\left({ }^{\circ} \mathrm{C}\right)\end{array}$ & $\begin{array}{l}\varepsilon \\
(\%) \\
\end{array}$ & $\begin{array}{l}\dot{\varepsilon} \\
\left(\mathrm{s}^{-1}\right)\end{array}$ & $\begin{array}{l}\text { ave } \\
\text { (mrd) }\end{array}$ & $\begin{array}{l}\max \\
(\mathrm{mrd})\end{array}$ & $\begin{array}{l}\text { ave } \\
(\mathrm{GPa})\end{array}$ & $\begin{array}{l}\max \\
(\mathrm{GPa})\end{array}$ & $\begin{array}{l}\text { ave } \\
(\mathrm{mrd})\end{array}$ & $\begin{array}{l}\max \\
(\mathrm{mrd})\end{array}$ & $\begin{array}{l}\text { ave } \\
(\mathrm{GPa})\end{array}$ & $\begin{array}{l}\max \\
(\mathrm{GPa})\end{array}$ & $\begin{array}{l}\text { ave } \\
(\mathrm{GPa})\end{array}$ & $\begin{array}{l}\text { ave } \\
(\mathrm{GPa})\end{array}$ \\
\hline D1316 & $30 / 37$ & 4.3 & 400 & 34 & 0.0027 & 3.0 & 3.6 & 0.30 & 0.67 & 1.3 & 1.4 & 0.07 & 0.17 & 0.11 & 0.16 \\
\hline D1243 & $30 / 33$ & 4.5 & 200 & 44 & 0.0029 & 2.9 & 3.4 & 0.69 & 0.82 & 1.3 & 1.3 & 0.17 & 0.19 & 0.24 & 0.34 \\
\hline D1315 & $50 / 62$ & 3.8 & 400 & 33 & 0.0023 & 3.3 & 3.4 & 0.34 & 0.89 & 1.1 & 1.2 & 0.06 & 0.15 & 0.10 & 0.23 \\
\hline D1244 & $50 / 59$ & 4.0 & 200 & 50 & 0.0031 & 3.1 & 4.1 & 0.86 & 0.89 & 1.1 & 1.2 & 0.14 & 0.15 & 0.26 & 0.57 \\
\hline D1188 & $75 / 79$ & 3.8 & 400 & 23 & 0.0022 & 4.0 & 4.2 & 1.19 & 1.24 & 1.1 & 1.2 & 0.10 & 0.12 & 0.30 & 0.96 \\
\hline D1187 & $75 / 80$ & 4.8 & 100 & 32 & 0.0013 & 4.0 & 4.7 & 1.45 & 1.46 & 1.2 & 1.2 & 0.15 & 0.19 & 0.40 & 1.19 \\
\hline D1475 & $85 / 82$ & 4.0 & 400 & 44 & 0.0023 & 4.6 & 5.4 & 1.24 & 1.35 & 1.3 & 1.5 & 0.17 & 0.19 & 0.38 & 1.05 \\
\hline D1476 & $85 / 85$ & 4.3 & 200 & 51 & 0.0034 & 4.7 & 5.9 & 1.91 & 1.96 & 1.4 & 1.5 & 0.17 & 0.26 & 0.52 & 1.64 \\
\hline D1189 & 100 & $1.7 *$ & 800 & 50 & 0.0027 & 5.9 & 6.9 & 0.74 & 1.05 & - & - & - & - & - & - \\
\hline D1185 & 100 & 3.7 & 400 & 32 & 0.0020 & 8.0 & 11.8 & 2.13 & 2.25 & - & - & - & - & - & - \\
\hline
\end{tabular}

651 Table 1. Summary of run conditions and results from X-ray diffraction experiments. Volume

652 percent of $\mathrm{NaMgF}_{3}$ were before sintering (S) and from relative intensity of X-ray diffraction

653 peaks during experiments (X). Standard strains ( $\varepsilon$ ) are shown as percentages. The average steady

654 state stress and maximum differential stress $(-\Delta \sigma)$ and texture strength (pole density or "IPF

655 max") are shown for each run. Since $-\Delta \sigma$ vs. $\varepsilon$ does not plot steady state behavior for runs

656 D1316 an D1315 (Fig. 2b), all stresses above 20\% strain were averaged. Standard deviations for

$657-\Delta \sigma$ are $<0.006$. The average total estimated stress for an interconnected weak layer (IWL) and a

658 load bearing framework (LBF) have been calculated using equations (11) and (6), respectively,

659 in Handy (1994).

$660 *$ Pressure estimate is low because there is no thermal equation of state for $\mathrm{NaMgF}_{3}$ that can take

661 into account the high temperature in run D1189.

662

663

664 


\begin{tabular}{lclllllll}
\multicolumn{1}{c}{ NaMgF $_{\mathbf{3}}$} & \multicolumn{1}{c}{ NaCl } \\
\hline Run & - & D1187 & D1315 & D1316 & - & D1187 & D1315 & D1316 \\
Volume S/M(\%) & $75 / 64$ & $75 / 77$ & $50 / 50$ & $30 / 23$ & $25 / 36$ & $25 / 23$ & $50 / 50$ & $70 / 77$ \\
\hline Connectivity $(\%)$ & 99.98 & 99.98 & 99.71 & 96.25 & 99.09 & 95.60 & 99.79 & 99.98 \\
Median cluster volume $\left(\mu \mathrm{m}^{3}\right)$ & 0.80 & 1.65 & 3.30 & 3.30 & 1.61 & 3.02 & 3.02 & 1.92 \\
Average aspect ratio & 1.25 & 2.85 & 3.47 & 3.61 & 1.60 & 3.20 & 3.29 & 3.10 \\
Final strain $(\%)$ & 0 & 32 & 33 & 34 & 0 & 32 & 33 & 34 \\
\hline
\end{tabular}

665 Table 2. Statistics for $\mathrm{NaMgF}_{3}$ and $\mathrm{NaCl}$ from X-ray microtomography analysis. The first

666 column in italics gives statistics for the undeformed $75 \% \mathrm{NaMgF}_{3}$ sample. Both percentages

667 measured before sintering (S), and percentages taken from microtomography (M) are shown.

668

669

\begin{tabular}{lrcccccccccccccc}
\hline Slip systems & & $(100)$ & $(100)$ & $(010)$ & $(001)$ & $(001)$ & $(001)$ & $\{111\}$ & Tot & & $\{111\}$ & $\{110\}$ & $\{100\}$ & Tot \\
& & {$[010]$} & $\langle 011\rangle$ & $\langle 101\rangle$ & {$[100]$} & {$[010]$} & $\langle 110\rangle$ & $\langle 101\rangle$ & $(\%)$ & & $\langle 10 \overline{1}\rangle$ & $\langle\overline{1} 10\rangle$ & $\langle 011\rangle$ & $(\%)$ \\
\hline CRSS & $\mathrm{MgSiO}_{3}$ & 3 & 4 & - & 1 & 1 & 1 & - & & $\mathrm{MgO}$ & 0.75 & 0.50 & 1.00 & \\
& $\mathrm{NaMgF}_{3}$ & 0.5 & 0.5 & 10 & 5 & 5 & 5 & 50 & & $\mathrm{NaCl}$ & 2.50 & 0.25 & 3.00 & \\
\hline VPSC & $25 \%$ vol & 2.5 & 13.6 & 0.0 & 0.0 & 0.2 & 0.2 & 0.0 & 16.5 & $75 \%$ vol & 8.2 & 63.9 & 11.4 & 83.5 \\
act(\%) & $75 \%$ vol & 7.8 & 51.4 & 0.2 & 0.1 & 1.7 & 2.1 & 0.0 & 63.3 & $25 \%$ vol & 5.6 & 23.3 & 7.9 & 36.8 \\
& $100 \%$ vol & 10.2 & 79.3 & 0.4 & 0.1 & 4.4 & 5.4 & 0.2 & 100.0 & $0 \%$ vol & - & - & - & - \\
\hline VPFFT & $\mathrm{R} 25 \%$ vol & 1.7 & 10.3 & 0.1 & 0.0 & 1.3 & 1.5 & 0.1 & 14.9 & $\mathrm{R} 75 \%$ vol & 12.9 & 53.9 & 18.4 & 85.1 \\
act(\%) & $\mathrm{R} 75 \%$ vol & 5.9 & 40.3 & 0.7 & 0.1 & 7.2 & 8.3 & 2.4 & 64.9 & $\mathrm{R} 25 \%$ vol & 6.9 & 18.3 & 10.0 & 35.1 \\
& $\mathrm{R} 100 \%$ vol & 8.1 & 58.0 & 1.1 & 0.1 & 1.6 & 13.4 & 7.8 & 100.0 & $\mathrm{R} 0 \%$ vol & - & - & - & - \\
& $\mathrm{P} 75 \%$ vol & 5.6 & 38.0 & 0.4 & 0.1 & 4.7 & 5.5 & 0.6 & 54.8 & $\mathrm{P} 25 \%$ vol & 10.4 & 19.6 & 15.2 & 45.2 \\
\hline
\end{tabular}

670 Table 3. Relative CRSS of $\mathrm{MgSiO}_{3}$ and $\mathrm{MgO}$ inferred from $\mathrm{CPO}$ observations for pressures of

$671>35$ GPa obtained in DAC (Wenk et al. 2011) compared to relative CRSS assigned to slip

672 systems for $\mathrm{NaMgF}_{3}$ and $\mathrm{NaCl}$ inferred with VPSC in this study. Activity percentages are listed

673 for $\mathrm{NaMgF}_{3}$ and $\mathrm{NaCl}$ following $30 \%$ axial shortening for various sample compositions and

674 random (R) and percolate (P) VPFFT microstructures corresponding to IPFs in Fig. 3b,c.

675 


\section{$676 \quad$ Figures}
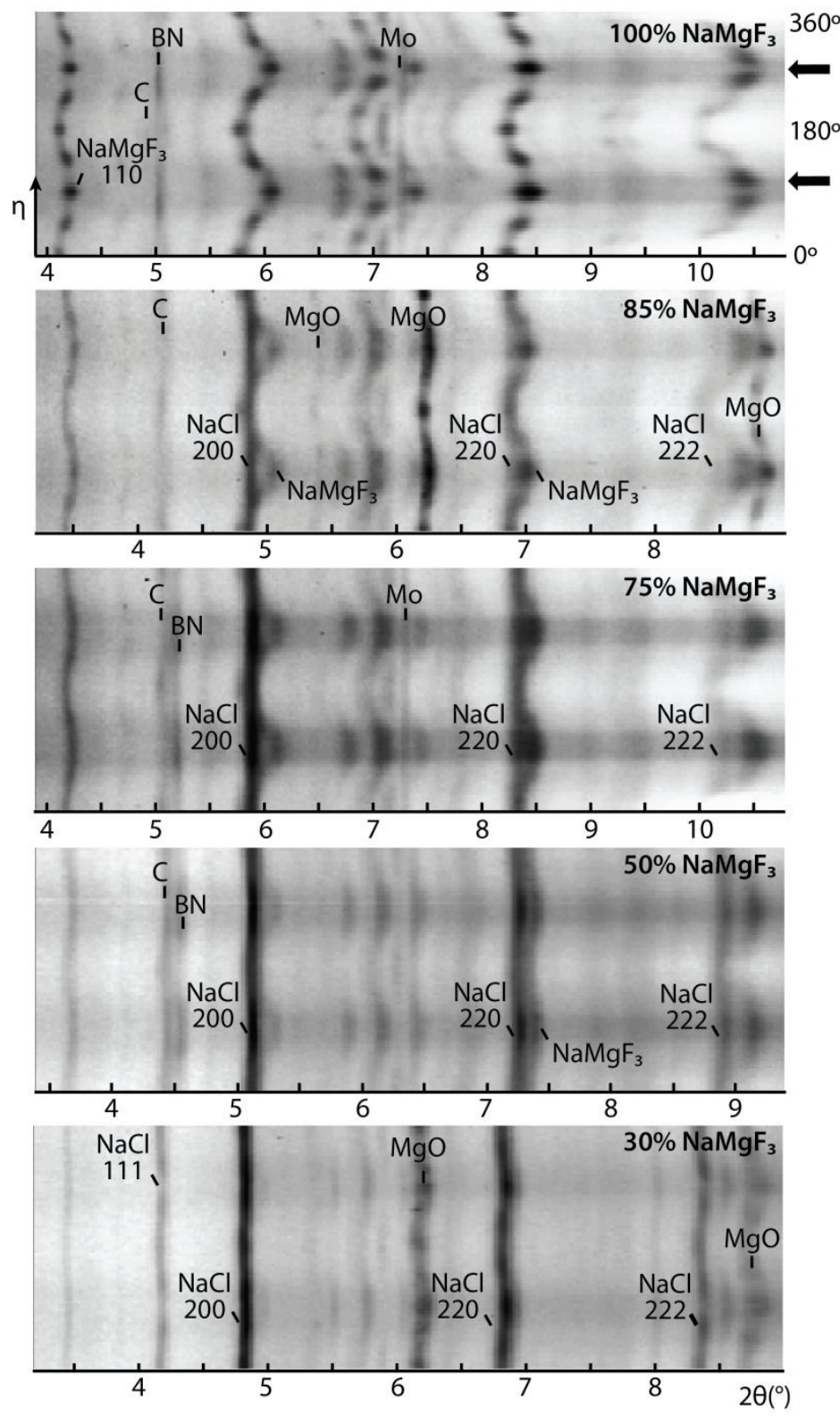

678 Figure 1. Unrolled diffraction patterns for samples at 20 tons ( 4 GPa), $100-400^{\circ} \mathrm{C}$, and $30 \%$

679 strain for all compositions. Peaks from the graphite heater $(\mathrm{C})$, the insulation sleeve, either boron

680 nitride $(\mathrm{BN})$ or $\mathrm{MgO}$, and small Mo contamination are labeled. The first $\mathrm{NaMgF}_{3}$ peak, 110 , is

681 labeled. However, because diffraction from multiple $\mathrm{NaMgF}_{3}$ planes contribute to each of the 
682 other peaks, these are not labeled. All unlabeled peaks are $\mathrm{NaMgF}_{3}$. Compression direction is 683 labeled with arrows in first image.

684

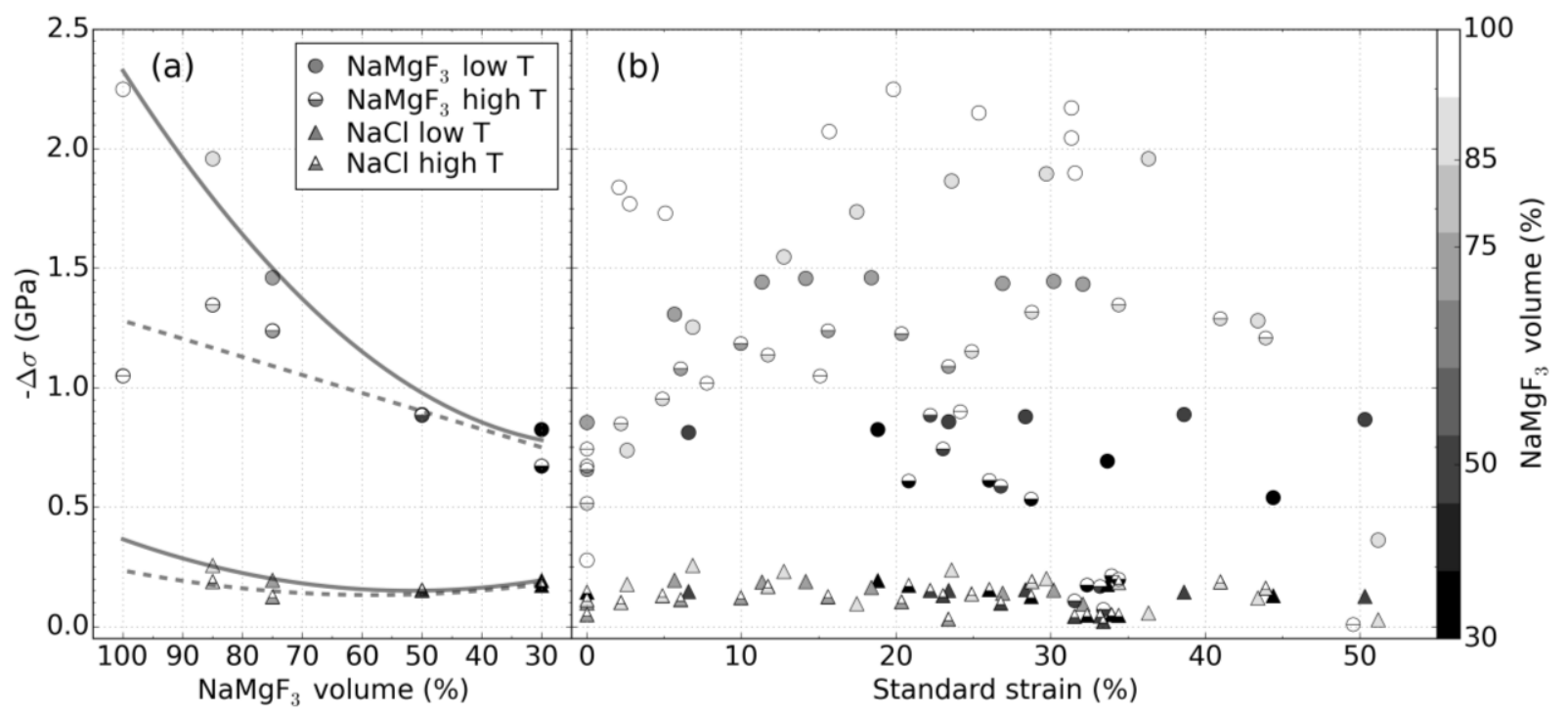

685

Figure 2. (a) Scatter plot of maximum differential stress $(-\Delta \sigma)$ versus composition in $\mathrm{NaMgF}_{3}$

687 and $\mathrm{NaCl}$ for each run (see Table 1 for values). All compositions were deformed twice, once at

688 higher average temperature (half-filled circles) and once at lower average temperature (filled

689 circles). Best-fit functions are given for average higher temperatures (dashed lines) and lower

690 average temperatures (solid lines) for each phase. (b) Scatter plot of $-\Delta \sigma$ versus standard strain in

$691 \mathrm{NaMgF}_{3}$ and $\mathrm{NaCl}$ for ten experimental runs. Composition indicated by gray scale. All data

692 shown was collected at 20 tons during sample compression. 


\section{(a) Experiments}

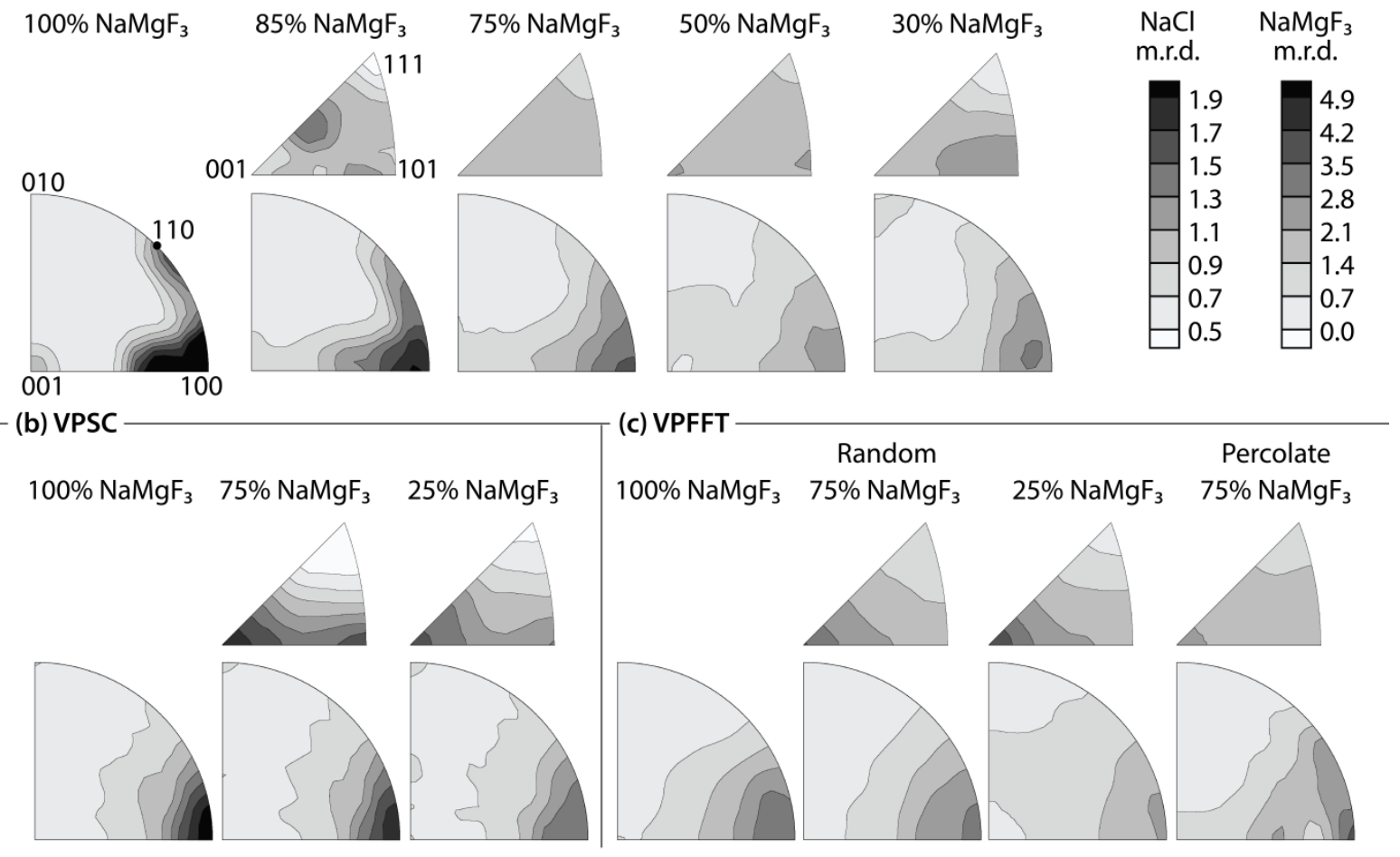

Figure 3. Inverse pole figures (IPFs) from (a) experiments, which correspond to 2D plots shown

695 in Fig. 2, collected at $\sim 4 \mathrm{GPa}, 100-400^{\circ} \mathrm{C}$, and $\sim 30 \%$ strain, (b) VPSC simulations with relative

696 CRSS assigned as shown in Table 3 to $30 \%$ strain, and (c) VPFFT simulations for the "random"

697 microstructures and the "percolate" microstructure to 30\% strain. Major crystallographic

698 directions are labeled for both $\mathrm{NaCl}$ (top row) and $\mathrm{NaMgF}_{3}$ (bottom row) in (a) and are mapped

699 relative to the compression direction in all maps. Pole densities are given in multiples of random

700 distribution (m.r.d.). An m.r.d. of 1 indicates random orientation. Equal area projections. 


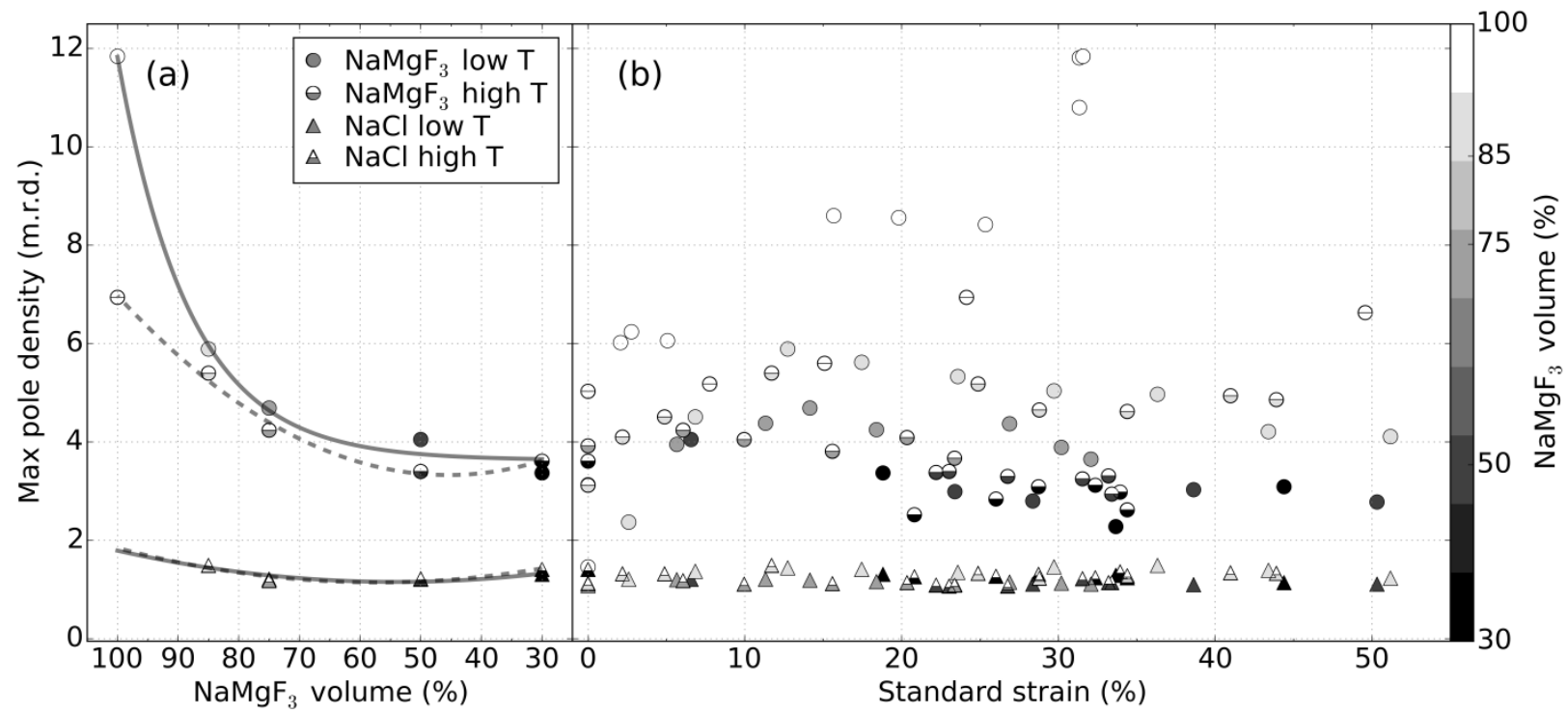

704 Figure 4. (a) Scatter plot of maximum IPF pole density versus composition for $\mathrm{NaMgF}_{3}$ and

705

706

707

708
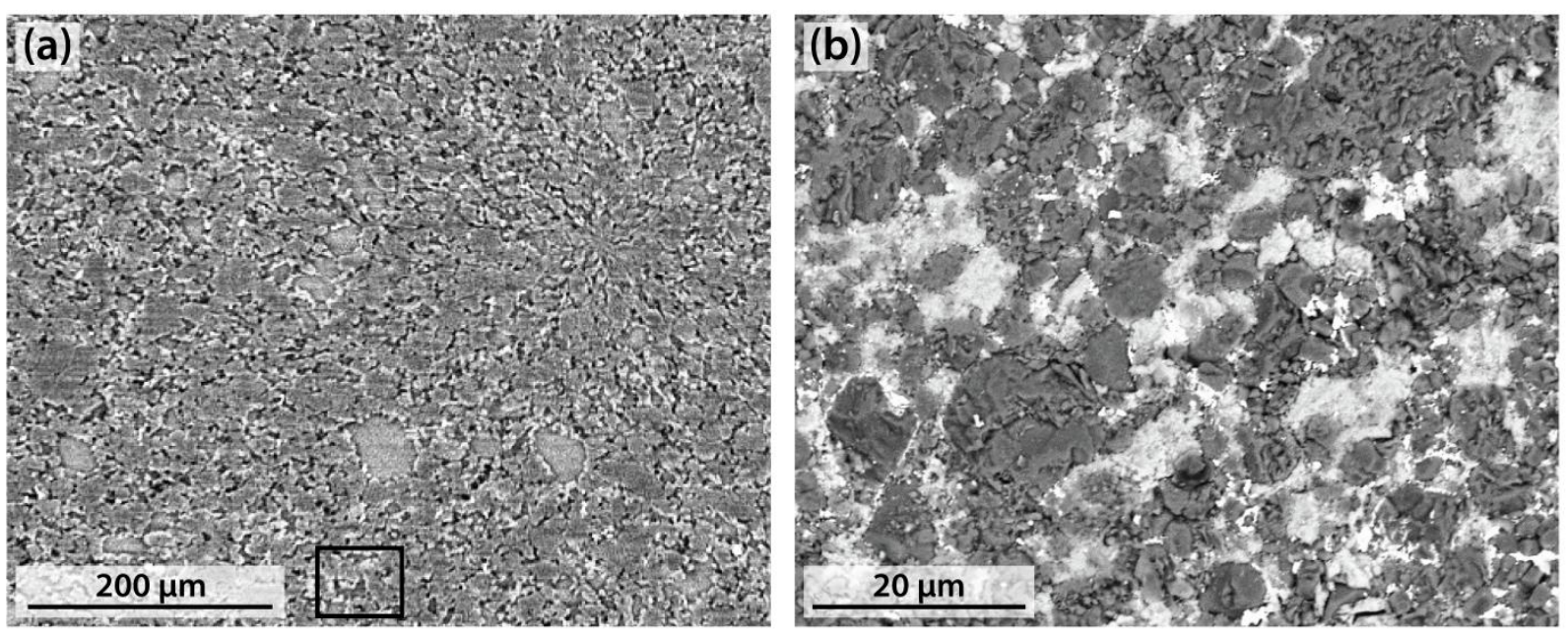

Figure 5. Cross sectional slices of an undeformed sample with composition $75 \% \mathrm{NaMgF}_{3}$ (darker 
714 gray) and $25 \% \mathrm{NaCl}$ (lighter gray) collected with (a) microtomography and (b) a scanning

715 electron microscope at $1000 \times$ magnification. The black rectangle in (a) shows the relative size of 716 the entire area of (b).

717

718

(a)

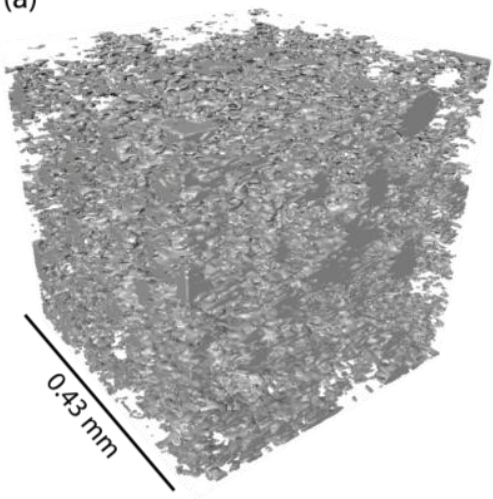

(b)

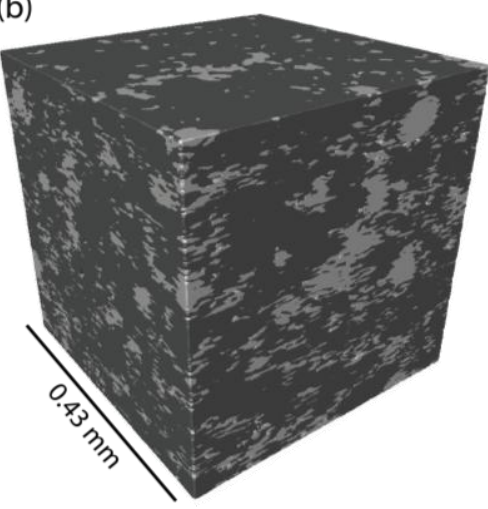

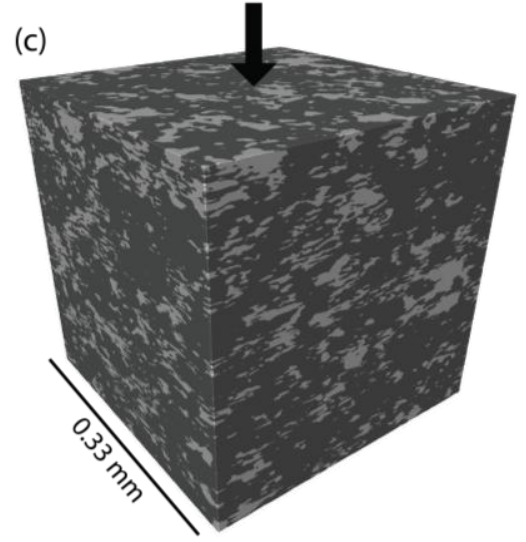

719 Figure 6. Three-dimensional microtomography images of (a) $\mathrm{NaCl}$ in an undeformed $75 \%$

$720 \mathrm{NaMgF}_{3}$ sample, (b) both phases in an undeformed $75 \% \mathrm{NaMgF}_{3}$ sample, and (c) both phases in

721 a $75 \% \mathrm{NaMgF}_{3}$ sample deformed to $30 \%$ strain. $\mathrm{NaMgF}_{3}$ grains are shown in darker gray, and

$722 \mathrm{NaCl}$ grains are shown in lighter gray. Compression direction indicated by the arrow. 
Random structure

$75 \% \mathrm{NaMgF}_{3}$
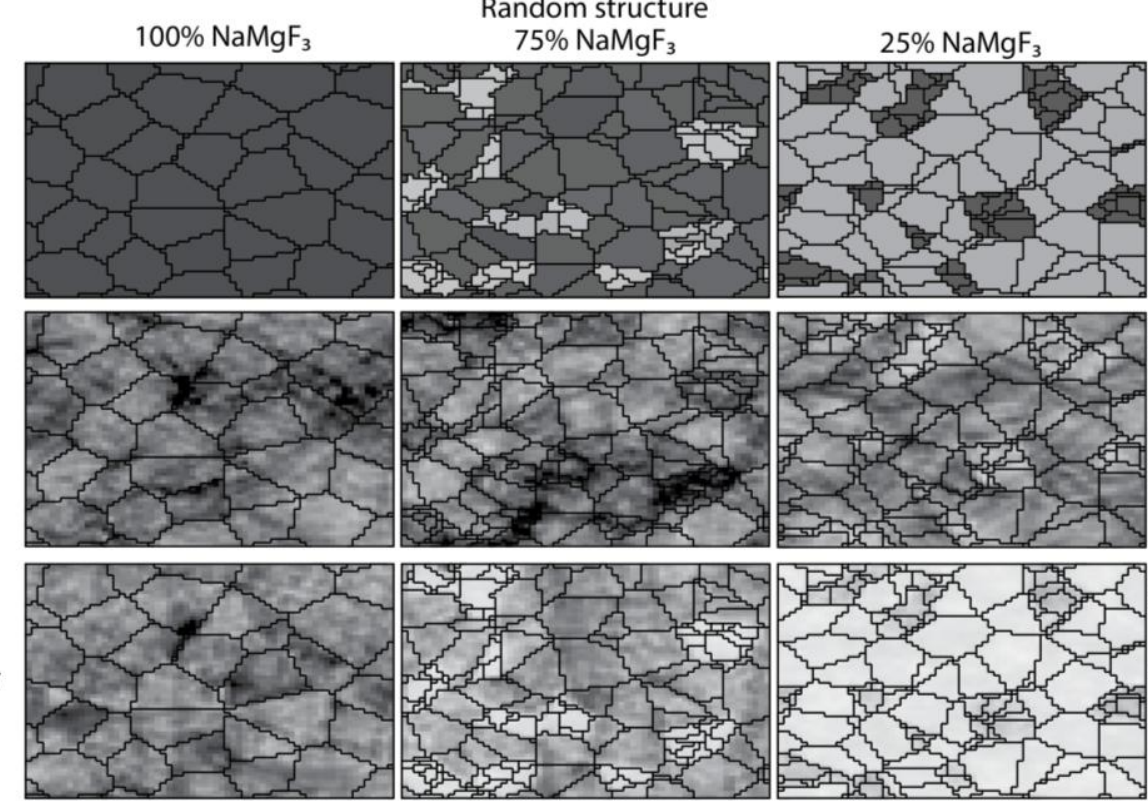

Percolate structure $75 \% \mathrm{NaMgF}_{3}$
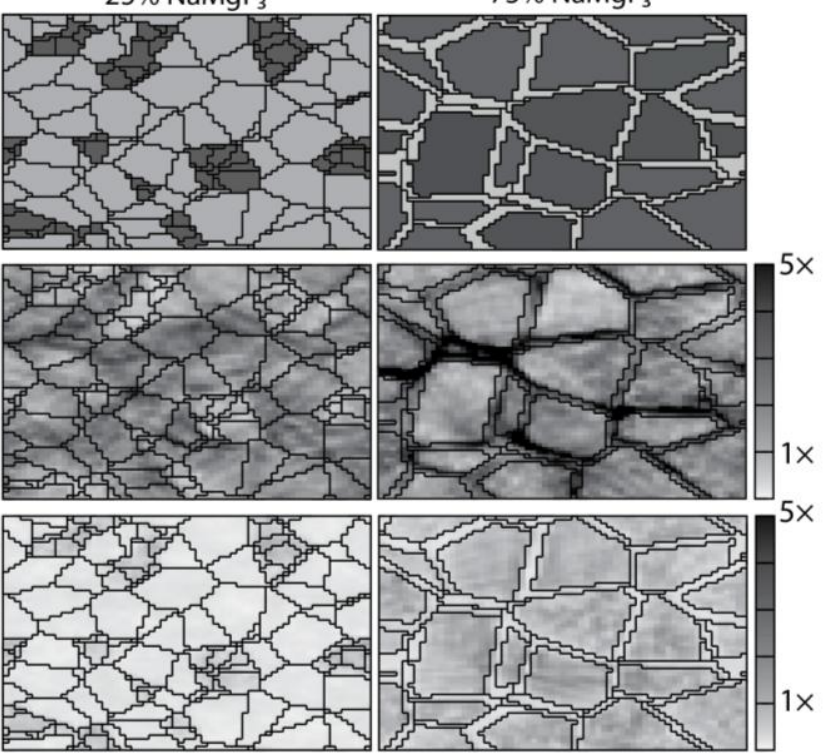

Figure 7. Maps of VPFFT microstructures with darker gray $\mathrm{NaMgF}_{3}$ grains and lighter gray

$\mathrm{NaCl}$ grains (top row), average strain rate $(\dot{\varepsilon})$ maps (middle row), and average stress maps $(-\Delta \sigma)$

(bottom row) with fastest strain rates and highest stresses shown in black. Homogenously deformed to $30 \%$ strain.

\section{References}

1. Amodeo, J., Carrez, P., Cordier, P. (2012). Modelling the effect of pressure on the critical shear stress of MgO single crystals. Philosophical Magazine, 92: 1523-1541, doi:10.1080/14786435.2011.652689.

2. Barnhoorn A, Bystricky M, Kunze K, Burlini L, Burg JP (2005) Strain localization in bimineralic rocks: Experimental deformation of synthetic calcite-anhydrite aggregates. Earth and Planetary Science Letters, 240: 748-763.

3. Carter NL, Heard HC (1970) Temperature and rate dependent deformation of halite. American Journal of Science, 269: 193-249. 
4. Cordier P, Ungár T, Zsoldos L, Tichy G (2004) Dislocation creep in $\mathrm{MgSiO}_{3}$ perovskite at conditions of the Earth's uppermost lower mantle. Nature, 428: 837-840.

5. Cottaar S, Li M, McNamara A, Wenk HR, Romanowicz B (2014) Synthetic seismic anisotropy models within a slab impinging on the core-mantle boundary. Geophysical Journal International, 199(1): 164-177.

6. Day RB, Stokes RJ (1966) Mechanical behavior of polycrystalline magnesium oxide at high temperatures. Journal of The American Ceramic Society 49,7:345-354.

7. Diard O, Leclereq S, Rousselier G, Cailletaud G (2005) Evaluation of finite element based analysis of 3D multicrystalline aggregates plasticity - application to crystal plasticity model identification and the study of stress and strain fields near grain boundaries. International Journal of Plasticity, 21: 691.

8. Eshelby JD (1957) The determination of the elastic field of an ellipsoidal inclusion, and related problems. Proceedings of the Royal Society A, 241(1226): 376-396.

9. Franssen RCMW (1994) The rheology of synthetic rocksalt in uniaxial compression. Tectonophysics, 233: 1-40.

10. French SW, Romanowicz BA (2014) Whole-mantle radially anisotropic shear velocity structure from spectral-element waveform tomography. Geophysical Journal International, 199: 1303-1327.

11. French SW, Romanowicz BA (2015) Broad plumes rooted at the base of the Earth's mantle beneath major hotspots. Nature, 525: 95-99.

12. Frost HJ, Ashby MF (1982) Deformation-mechanism maps: The plasticity and creep of metals and ceramics. Pergamon Press, New York. 
13. Girard J, Amulele G, Farla R, Mohiuddin A, Karato SI (2016) Shear deformation of bridgmanite and magnesiowüstite aggregates at lower mantle conditions. Science, 351(6269): 144-147.

14. Handy (1994) Flow laws for rocks containing two non-linear viscous phases: a phenomenological approach. Journal of Structural Geology, 16(3): 287-301.

15. Herwegh M, Berger A (2004) Deformation mechanisms in second-phase affected microstructures and their energy balance. Journal of Structural Geology, 26: 1483-1498.

16. Kaercher PM (2014) Crystallographic preferred orientation and deformation of deep Earth minerals. Dissertation, University of California, Berkeley.

17. Kaercher P, Speziale S, Miyagi L, Kanitpanyacharoen W, Wenk HR (2012) Crystallographic preferred orientation in wüstite $(\mathrm{FeO})$ through the cubic-torhombohedral phase transition. Physics and Chemistry of Minerals, 39: 613-626.

18. Karato SI, Zhang S, Wenk HR (1995) Superplasticity in Earth's lower mantle: Evidence from seismic anisotropy and rock physics. Science 270(5235), 458-461.

19. Kraych A, Carrez P, Hirel P, Clouet E, Cordier P (2016). On dislocation glide in $\mathrm{MgSiO}_{3}$ bridgmanite at high-pressure and high-temperature. Earth and Planetary Science Letters, 452: 60-68, doi: 10.1016/j.eps1.2016.07.035.

20. Lebensohn RA (2001) N-site modeling of a 3D viscoplastic polycrystal using fast fourier transform. Acta Materialia, 49: 2723-2737.

21. Lebensohn RA, Tomé CN (1993) A self-consistent anisotropic approach for the simulation of plastic deformation and texture development of polycrystals: application to zirconium alloys. Acta Metallurgica Materialia, 9: 2611-2624. 
22. Lebensohn RA, Zecevic M, Knezevic M, McCabe RJ (2016) Average intragranular misorientation trends in polycrystalline materials predicted by a viscoplastic selfconsistent approach. Acta Materialia 104: 228-236.

23. Lewis MH, Bright MWA (1985) Transformation twinning in synthetic neighborite. The American Mineralogist, 56: 1519-1526.

24. Li L, Addad A, Weidner D, Long H, Chen J (2007) High pressure deformation in twophase aggregates. Tectonophysics, 439: 107-117.

25. Li M, McNamara AK, Garnero EJ (2014) Chemical complexity of hotspots caused by cycling oceanic crust through mantle reservoirs. Nature Geoscience, 7: 366-370.

26. Liu L, Bi Y, Xu J, Chen X (2010) Ab initio study of the elastic properties of sodium chloride at high pressure. Physica B, 405: 2175-2180.

27. Lutterotti L, Vasin R, Wenk HR (2014) Rietveld texture analysis from synchrotron diffraction images: I. Calibration and basic analysis. Powder Diffraction, 29(1): 76-84.

28. Madi K, Forest S, Cordier P, Boussuge M (2005) Numerical study of creep in two-phase aggregates with a large rheology contrast: Implications for the lower mantle. Earth and Planetary Science Letters, 237: 223-238.

29. Mainprice D, Tommasi A, Ferré D, Carrez P, Cordier P (2008) Predicted glide systems and crystal preferred orientations of polycrystalline silicate Mg-Perovskite at high pressure: Implications for the seismic anisotropy in the lower mantle. Earth and Planetary Science Letters, 271: 135-144.

30. Marquardt H, Miyagi L (2015) Slab stagnation in the shallow lower mantle linked to an increase in mantle viscosity. Nature Geoscience, 8(4): 311-314. 
31. Martinez I, Wang Y, Guyot F, Liebermann RC (1997) Microstructures and iron partitioning in $(\mathrm{Mg}, \mathrm{Fe}) \mathrm{SiO}_{3}$ perovskite-( $\left.\mathrm{Mg}, \mathrm{Fe}\right) \mathrm{O}$ magnesiowüstite assemblages: $\mathrm{An}$ analytical transmission electron microscopy study. Journal of Geophysical Research, 102 (B3): 5265-5280.

32. Meade C, Silver PG (1995) Laboratory and seismological observations of lower mantle isotropy. Geophysical Research Letters, 22(10): 1293-1296.

33. McNamara AK, van Keken PE, Karato SI (2002) Development of anisotropic structure in the Earth's lower mantle by solid-state convection. Nature, 415: 310-314.

34. Merkel S, Wenk HR, Badro J, Montagnac G, Gillet P, Mao HK, Hemley RJ (2003) Deformation of $\left(\mathrm{Mg}_{0.9}, \mathrm{Fe}_{0.1}\right) \mathrm{SiO}_{3}$ perovskite aggregates up to $32 \mathrm{GPa}$. Earth and Planetary Science Letters, 209: 351-360.

35. Merkel S, Wenk HR, Shu J, Shen G, Gillet P, Mao HK, Hemley RJ (2002) Deformation of polycrystalline $\mathrm{MgO}$ at pressures of the lower mantle. Journal of Geophysical Research 107, B11: 2271.

36. Miyagi LM, Wenk HR (2016) Texture development and slip systems in bridgmanite and bridgmanite + ferropericlase aggregates. Physics and Chemistry of Minerals, DOI 10.1007/s00269-016-0820-y.

37. Oganov AR, Ono S (2004) Theoretical and experimental evidence of a post-perovskite phase of $\mathrm{MgSiO}_{3}$ in Earth's D', layer. Nature, 430: 445-448.

38. Poirier JP, Beauchesne S, Guyot F (1989) Deformation mechanisms of crystals with perovskite structure In: A Navrotsky and DJ Weidner Eds., Perovsite: A Structure of Great Interest to Geophysics and Materials Science, AGU Geophysical Monograph Series, 45: 119-123. 
39. Routbort JL (1979) Work hardening and creep of MgO. Acta Metallurgica 27: 649-661.

40. Solomatov VS, El-Khozondar R, Tikare V (2002) Grain size in the lower mantle: constraints from numerical modeling of grain growth in two-phase systems. Physics of the Earth and Planetary Interiors, 129: 265-282.

41. Tackley PJ (2000) Mantle convection and plate tectonics: toward an integrated physical and chemical theory. Science, 288: 2002-2006.

42. Tullis J, Wenk HR (1994) Effect of muscovite on the strength and lattice preferred orientations of experimentally deformed quartz aggregates. Materials Science and Engineering, A175: 209-220.

43. Umemoto K, Wentzcovitch RM, Weidner DJ, Parise JB (2006) $\mathrm{NaMgF}_{3}$ : A low-pressure analog of $\mathrm{MgSiO}_{3}$. Geophysical Research Letters, 33: L15304.

44. Umemoto K, Wentzcovitch RM (2011) Two-stage dissociation in $\mathrm{MgSiO}_{3}$ postperovskite. Earth and Planetary Science Letters, 311: 225-229.

45. Voronoi GF (1908) Nouvelles applications des paramètres continus à la théorie de formes quadratiques. Journal für die reine und angewandte Mathematik, 134: 198-287.

46. Wang Y, Durham W, Getting IC, Weidner DJ (2003) The deformation-DIA: A new apparatus for high temperature triaxial deformation to pressures up to $15 \mathrm{GPa}$. Review of Scientific Instruments, 74(6): 3002-3011.

47. Wang Y, Guyot F, Yeganeh-Haeri A, Liebermann RC (1990) Twinning in $\mathrm{MgSiO}_{3}$ perovskite. Science, 248: 468-471.

48. Wang Y, Hilairet N, Nishiyama N, Yahata N, Tsuchiya T, Morard G, Fiquet G (2013) High-pressure, high-temperature deformation of $\mathrm{CaGeO}_{3}$ (perovskite) $\mathrm{MgO}$ aggregates: 
Implications for multiphase rheology of the lower mantle. Geochemistry Geophysics Geosystems, 14(9): 3389-3408.

49. Wenk HR, Armann M, Burlini L, Kunze K, Bortolotti M (2009) Large strain shearing of halite: Experimental and theoretical evidence for dynamic texture changes. Earth and Planetary Science Letters, 280: 205-210.

50. Wenk HR, Canova G, Molinari A, Mecking H (1989) Texture development in halite: comparison of taylor model and self-consistent theory. Acta Metallurgica, 37(7): 20172029.

51. Wenk HR, Cottaar S, Tomé C, McNamara A, Romanowicz B (2011) Deformation in the lowermost mantle: From polycrystal plasticity to seismic anisotropy. Earth and Planetary Science Letters, 306: 33-45.

52. Wenk HR, Speziale S, McNamara AK, Garnero EJ (2006) Modeling lower mantle anisotropy development in a subducting slab. Earth and Planetary Science Letters, 245: $302-314$

53. Wenk HR, Lonardelli I, Pehl J, Devine J, Prakapenka V, Shen G, Mao HK (2004) In situ observation of texture development in olivine, ringwoodite, magnesiowüstite and silicate perovskite at high pressure. Earth and Planetary Science Letters, 226: 507-519.

54. Yamazaki D, Yoshino T, Nakakuki T (2014) Interconnection of ferro-periclase controls subducted slab morphology at the top of the lower mantle. Earth and Planetary Science Letters, 403: 352-357.

55. Yamazaki D, Karato SI (2001) Some mineral physics constraints on the rheology and geothermal structure of Earth’s lower mantle. American Mineralogist, 86: 385-391. 
56. Zhao Y, Weidner DJ (1993) The single crystal elastic moduli of neighborite. Physics and Chemistry of Minerals, 20: 419-424.

57. Zhao Y, Weidner DJ, Ko J, Leinenweber K, Liu X, Li B, Meng Y, Pacalo REG, Vaughan MT, Wang Y, Yeganeh-Haeri A (1994) Perovskite at high P-T conditions: An in situ synchrotron $\mathrm{X}$ ray diffraction study of $\mathrm{NaMgF}_{3}$ perovskite. Journal of Geophysical Research, 99(B2): 2871-2885. 